\title{
Advances and challenges in understanding the electrocatalytic conversion of carbon dioxide to fuels
}

\author{
Yuvraj Y. Birdja $\circledast^{1,2}$, Elena Pérez-Gallent ${ }^{1,3}$, Marta C. Figueiredo ${ }^{1,4}{ }^{1}$, Adrien J. Göttle1, \\ Federico Calle-Vallejo ${ }^{1,5 \star}$ and Marc T. M. Koper ${ }^{1 *}$
}

The electrocatalytic reduction of carbon dioxide is a promising approach for storing (excess) renewable electricity as chemical energy in fuels. Here, we review recent advances and challenges in the understanding of electrochemical $\mathrm{CO}_{2}$ reduction. We discuss existing models for the initial activation of $\mathrm{CO}_{2}$ on the electrocatalyst and their importance for understanding selectivity. Carbon-carbon bond formation is also a key mechanistic step in $\mathrm{CO}_{2}$ electroreduction to high-density and high-value fuels. We show that both the initial $\mathrm{CO}_{2}$ activation and $\mathrm{C}-\mathrm{C}$ bond formation are influenced by an intricate interplay between surface structure (both on the nano- and on the mesoscale), electrolyte effects $(\mathrm{pH}$, buffer strength, ion effects) and mass transport conditions. This complex interplay is currently still far from being completely understood. In addition, we discuss recent progress in in situ spectroscopic techniques and computational techniques for mechanistic work. Finally, we identify some challenges in furthering our understanding of these themes.

W ith the growing importance and falling prices of renewable electricity, the issue of electricity storage to deal with the intermittent nature of renewable energy sources is becoming urgent. Storing renewable electricity in chemical bonds ('electrofuels') is particularly attractive, as it allows for high-energy-density storage and potentially high flexibility. While hydrogen is the most likely and realistic candidate for electricity storage in electrofuels, research on the electrochemical conversion of carbon dioxide and water into carbon-based fuels has intrigued electrochemists for decades, and is currently undergoing a notable renaissance ${ }^{1-4}$. In contrast to hydrogen production by water electrolysis, carbon dioxide electrolysis is still far from a mature technology. Significant hurdles regarding energy efficiency, reaction selectivity and overall conversion rate need to be overcome if electrochemical carbon dioxide reduction is to become a viable option for storing renewable electricity.

Many electrocatalysts have been reported for the production of different compounds from the electrocatalytic carbon dioxide reduction reaction $\left(\mathrm{CO}_{2} \mathrm{RR}\right)$. Table 1 gives an overview of some of the most active and selective metal or metal-derived electrocatalysts towards specific products in aqueous media. The two-electron transfer products, $\mathrm{CO}$ and $\mathrm{HCOOH}$, can be produced with low overpotential and high Faradaic efficiency on suitable electrocatalysts, but substantially higher overpotentials and lower selectivities are observed for multi-electron transfer products such as methane, ethylene and alcohols ${ }^{2}$. For a recent discussion about the economic perspectives of $\mathrm{CO}_{2} \mathrm{RR}$, the reader is referred to a previous analysis ${ }^{5}$.

The aim of this Review is not to be exhaustive, but rather to selectively (and subjectively) discuss some recent advances and pertinent challenges in this field, focusing on themes that have recently witnessed important progress $s^{2,3,6,7}$. An overview of some of the themes covered in this Review is shown in Fig. 1. We also discuss two important methodologies used to increase fundamental understanding of $\mathrm{CO}_{2} \mathrm{RR}$ : in situ spectroscopic techniques and computational techniques.

\section{Initial activation of $\mathrm{CO}_{2}$}

The first step in the $\mathrm{CO}_{2} \mathrm{RR}$ is the activation of the $\mathrm{CO}_{2}$ molecule. It is often claimed that activation and reduction of $\mathrm{CO}_{2}$ is difficult because the first electron transfer to form the $\mathrm{CO}_{2}{ }^{-}$radical intermediate has a very negative redox potential $\left(-1.9^{\circ} \mathrm{V}\right.$ versus normal hydrogen electrode), or because $\mathrm{CO}_{2}$ is a very stable molecule $^{4}$. Neither statement is accurate. Electrocatalysts stabilize the $\mathrm{CO}_{2}{ }^{-}$radical or reaction intermediate by forming a chemical bond between $\mathrm{CO}_{2}$ and catalyst, leading to a less negative redox potential. With the right electrocatalyst, it is possible to reduce $\mathrm{CO}_{2}$ to $\mathrm{CO}$ or $\mathrm{HCOOH}$ at low overpotential. This low-overpotential reversible catalysis is related to the mechanism of a two-electron process, typically consisting of only one intermediate, which can be optimized using an appropriate catalyst ${ }^{8,9}$. Enzymes such as formate dehydrogenase and carbon monoxide dehydrogenase are indeed effective reversible catalysts for the $\mathrm{CO}_{2} \mathrm{RR}$ to formate and carbon monoxide, respectively, exhibiting negligible overpotentials ${ }^{10}$. In addition, the equilibrium potentials of $\mathrm{CO}_{2} \mathrm{RR}$ are close to $0 \mathrm{~V}$ (and sometimes higher), making the thermodynamic stability of $\mathrm{CO}_{2}$ similar to that of water.

We consider four redox reactions related to the activation of $\mathrm{CO}_{2}$ (equations (1)-(4)):

$$
*+\mathrm{CO}_{2}+\mathrm{H}^{+}+e^{-} \rightarrow{ }^{*} \mathrm{COOH}
$$

\footnotetext{
'Leiden Institute of Chemistry, Leiden University, Leiden, the Netherlands. 2Present address: Separation and Conversion Technology, Flemish Institute for Technological Research, Mol, Belgium. ${ }^{3}$ Present address: Department of Sustainable Process and Energy Systems, TNO, Delft, the Netherlands. ${ }^{4}$ Present address: Department of Chemical Engineering and Chemistry, Eindhoven University of Technology, Eindhoven, the Netherlands. ${ }^{5}$ Present address: Departament de Ciència de Materials i Química Fisica and Institut de Química Teòrica i Computacional, Universitat de Barcelona, Barcelona, Spain. *e-mail: f.calle.vallejo@ub.edu; m.koper@lic.leidenuniv.nl
} 


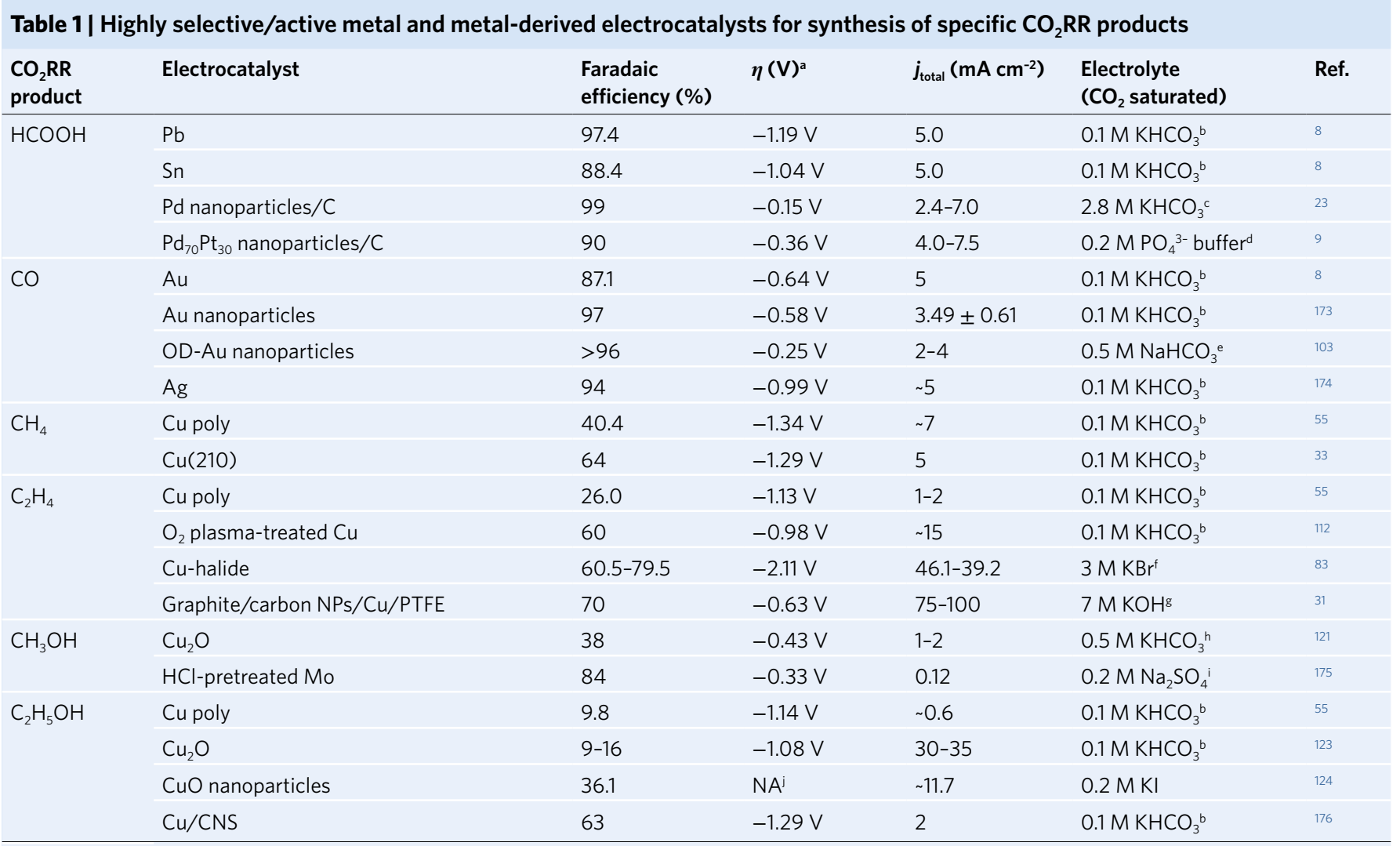

${ }^{\mathrm{a}} \eta=E-E^{0}$ with $E^{0}$ versus $\mathrm{RHE}$, where $\eta$ is overpotential, $E$ is applied potential and $E^{0}$ is standard electrode potential ${ }^{6} .{ }^{\mathrm{b}} \mathrm{pH} \approx 6.8 .{ }^{\mathrm{c}} \mathrm{pH} \approx 8.2 .{ }^{\mathrm{d}} \mathrm{pH} \approx 6.7 .{ }^{\mathrm{e}} \mathrm{pH} \approx 7.2 .{ }^{\mathrm{f}} \mathrm{pH} \approx 3 .{ }^{\mathrm{p}} \mathrm{pH}>14 .{ }^{\mathrm{h}} \mathrm{pH} \approx 7.6$. ${ }^{\mathrm{p}} \mathrm{pH} \approx 4.2 .{ }^{\mathrm{i}} \mathrm{At} E$ $=-1.7 \mathrm{~V}$ versus saturated calomel electrode $\left(\mathrm{pH}\right.$ not reported). $j_{\text {total }}$ total current density; $\mathrm{NA}$, not available.

$$
\begin{gathered}
*+\mathrm{CO}_{2}+\mathrm{H}^{+}+e^{-} \rightarrow{ }^{*} \mathrm{OCHO} \\
*+\mathrm{CO}_{2}+e^{-} \rightarrow{ }^{\star} \mathrm{CO}_{2}^{-} \\
*+\mathrm{H}^{+}+2 e^{-} \rightarrow{ }^{*} \mathrm{H}^{-}
\end{gathered}
$$

Equations (1) and (2) are so-called concerted proton-electron transfer (CPET) reactions and have been considered computationally for deriving trends in selectivity among (post-)transition metal surfaces ${ }^{11}$. The authors argued that ${ }^{*} \mathrm{COOH}$ is the more likely first intermediate for $\mathrm{CO}$ formation, and ${ }^{\star} \mathrm{OCHO}$ the more likely intermediate for formic acid production (an assertion that is generally agreed on in the literature). Using calculated binding energies, they generally find good agreement between their predictions and experiment: post-transition metals such as $\mathrm{Pb}$ and $\mathrm{Sn}$ prefer to bind $\mathrm{CO}_{2}$ via oxygen and are selective towards formic acid, whereas transition-metal electrodes prefer to bind via carbon. Interestingly, in two instances, their calculations deviate from the experimental observations in Table 1: silver is predicted to be an excellent catalyst for formic acid production, whereas palladium is predicted to have the lowest onset potential for CO production. They ascribe these differences to kinetic effects not included in their calculations.

Interestingly, in the molecular electrocatalysis community, the views on the initial activation of $\mathrm{CO}_{2}$ appear to be subtly different. The initial binding of $\mathrm{CO}_{2}$ to the catalyst does not involve a CPET step such as in equations (1) and (2), but rather an electron-transfer mediated $\mathrm{CO}_{2}$ binding step, as indicated by equation (3). The $\mathrm{CO}_{2}$ anionic adduct is generally bound to the metal centre of the catalyst. For instance, for a cobalt-(proto)porphyrin catalyst, $\mathrm{CO}_{2}$ binding takes place if the cobalt centre changes oxidation state from $\mathrm{Co}$ (II) to $\mathrm{Co}(\mathrm{I})$, with the electronic density flowing back onto the ${ }^{\star} \mathrm{CO}_{2}$ ligand, formally written as in equations (5) and (6).

$$
\begin{gathered}
\mathrm{Co}(i i)+e^{-} \rightarrow \mathrm{Co}(i) \\
\mathrm{Co}(i)+\mathrm{CO}_{2} \rightarrow \mathrm{Co}(i i)-\mathrm{CO}_{2}^{-}
\end{gathered}
$$

Subsequent protonation or CPET steps generate ${ }^{\star} \mathrm{COOH}$ or ${ }^{*} \mathrm{COOH}^{-}$intermediates $^{12}$. If equation (3) is rate determining or potential determining, the $\mathrm{pH}$ dependence of $\mathrm{CO}_{2}$ activation may differ from the $\mathrm{pH}$ dependence of the competing hydrogen evolution reaction (HER). This different $\mathrm{pH}$ dependence of the $\mathrm{CO}_{2} \mathrm{RR}$ and HER pathways was used to explain the strong $\mathrm{pH}$ dependence of the overall product selectivity on graphite-immobilized Co-protoporphyrin, with $\mathrm{H}_{2}$ being the primary product at $\mathrm{pH} 1$ but $\mathrm{CO}$ being the primary product at $\mathrm{pH} 3$ (refs. ${ }^{13,14}$ ). A similar mechanistic model was proposed for gold-catalysed $\mathrm{CO}_{2} \mathrm{RR}$, suggesting that also on gold the ${ }^{\star} \mathrm{CO}_{2}{ }^{-}$intermediate, and not ${ }^{\star} \mathrm{COOH}$, is the relevant activated form of $\mathrm{CO}_{2}$ (ref. ${ }^{15}$ ). Recent computational work has confirmed that on $\mathrm{Ag}(111){ }^{\star} \mathrm{CO}_{2}$ is highly sensitive to the presence of an electric field, as, for example, modelled by the presence of a cation ${ }^{16}$. Although the authors do not write the formation of ${ }^{\star} \mathrm{CO}_{2}$ as an electron-transfer step, the resulting ${ }^{\star} \mathrm{CO}_{2}$ is highly polarizable, and therefore sensitive to $\mathrm{pH}$ and cation effects (see 'Reaction and process conditions'). Similar conclusions regarding the importance of $\mathrm{a}^{*} \mathrm{CO}_{2}{ }^{\delta-}$ intermediate in the $\mathrm{CO}_{2} \mathrm{RR}$ reduction to $\mathrm{CO}$ on a $\mathrm{Ag}(110)$ electrode have been drawn based on kinetic simulations of CO formation using a multiscale model ${ }^{17}$.

A similar situation exists for formate/formic acid production on molecular catalysts. Among metalloporphyrins, Rh, Sn and In protoporphyrins have a high selectivity towards formic acid in aqueous electrolyte ${ }^{18}$. Density functional theory (DFT) calculations suggest that the key intermediate is an anionic hydride ${ }^{19}$, formed through equation (4), as previously suggested in the molecular catalysis 
a Initial activation

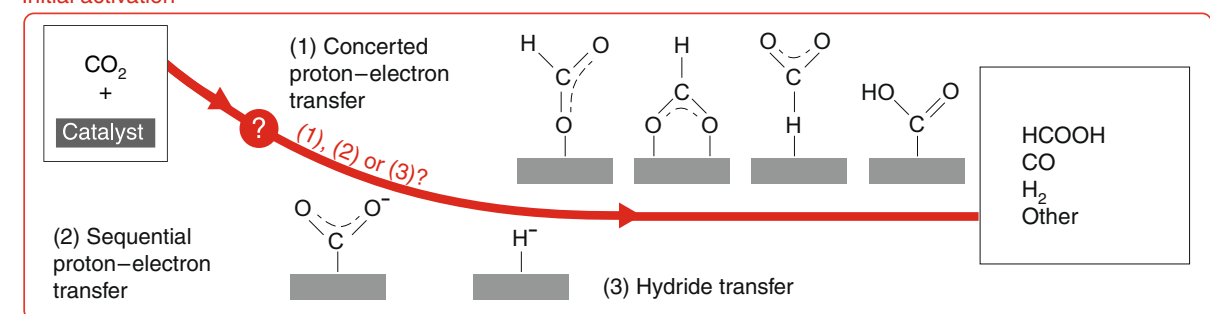

b

Electrode morphology
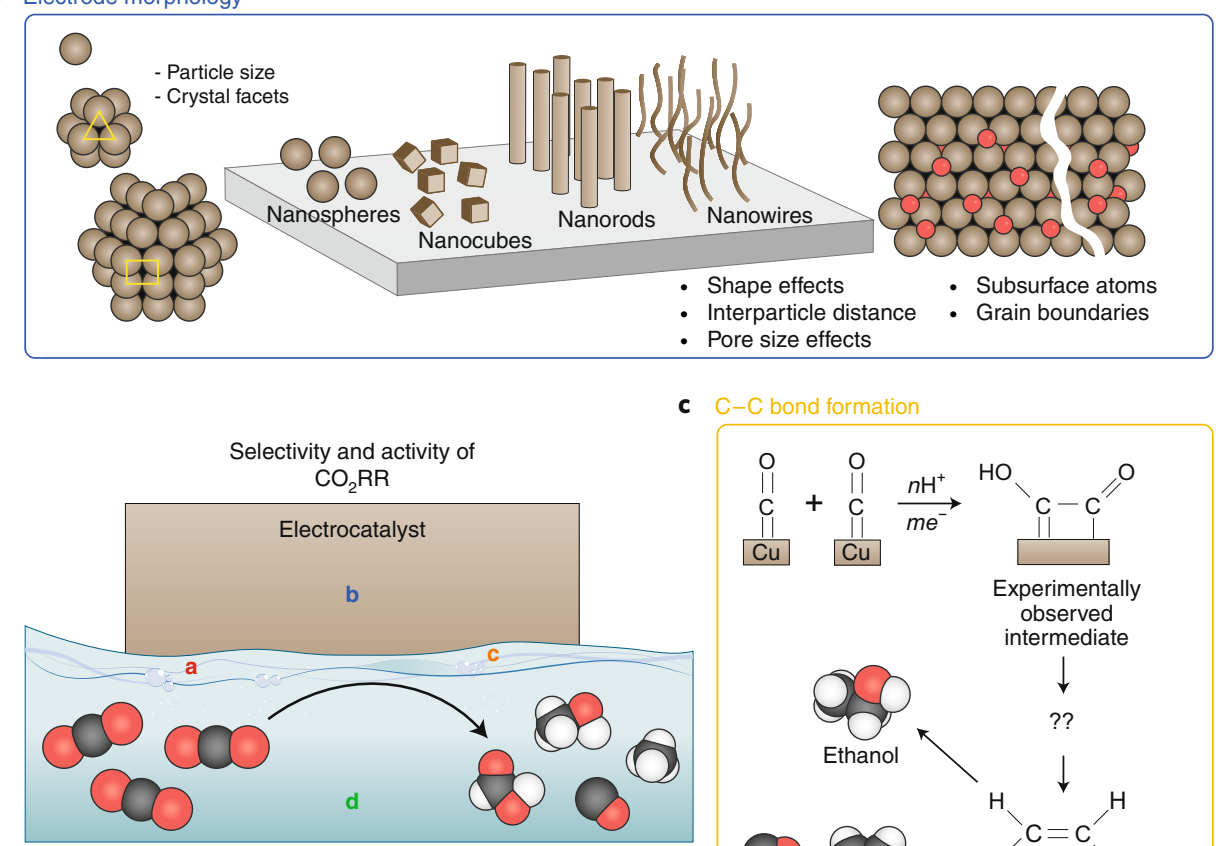

C

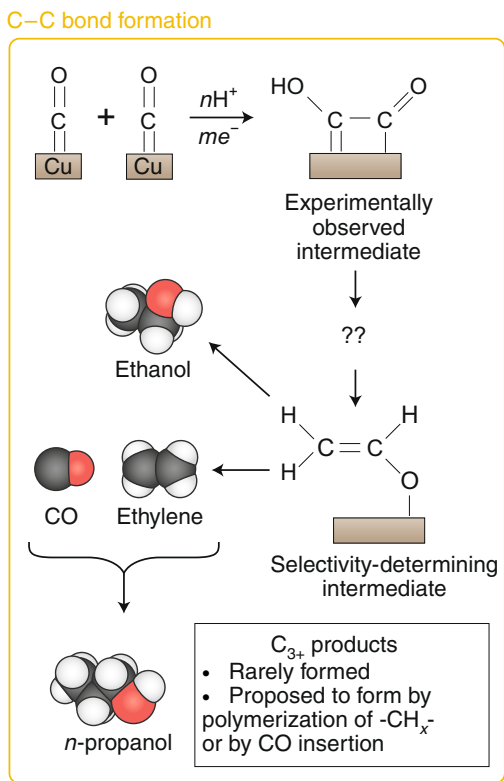

Fig. 1 | Overview of themes discussed in this review. $\mathbf{a}$, Initial activation of $\mathrm{CO}_{2}$, which can proceed via CPET, SPET or hydride-transfer mechanisms. b, Influence of the mesostructure of the electrode on the selectivity and activity of $\mathrm{CO}_{2} \mathrm{RR}$. $\mathbf{c}$, Recent views on $\mathrm{C}-\mathrm{C}$ bond formation from $\mathrm{CO}_{2} \mathrm{RR}$, specifically the formation of $\mathrm{C}_{2} \mathrm{H}_{4}$ and $\mathrm{C}_{3+}$ products. $\mathbf{d}$, The important role of reaction and process conditions, such as local pH, on $\mathrm{CO}_{2} \mathrm{RR}$ activity and selectivity.

literature ${ }^{20,21}$. The anionic hydride performs a nucleophilic attack on the carbon atom of $\mathrm{CO}_{2}$, yielding $\mathrm{HCOO}^{-}$. Again, the reaction is triggered by a potential-induced change in the oxidation state of the catalyst, either of the metal centre or the ligand, with the hydride residing on the metal or the ligand (the latter is the most likely pathway for In and Sn porphyrins). The stability of the resulting species is crucial to the subsequent elementary step and the formation of either $\mathrm{CO}$ or $\mathrm{HCOOH} / \mathrm{HCOO}^{-}$. Interestingly, such a (lattice-)hydride mechanism was recently proposed for nanostructured copper-hydride catalysts with a much enhanced selectivity for formic acid ('normal' copper yields primarily $\mathrm{CO}$ as a two-electron product $)^{22}$. The importance of a hydride-mediated pathway has also been suggested for formate production on palladium electrodes, as well as in solution ${ }^{23,24}$.

The relevance of considering equations (3) and (4) in the activation of $\mathrm{CO}_{2}$ as opposed to equations (1) and (2), is that the intermediates involved are charged (or strongly polarizable) and hence sensitive to $\mathrm{pH}$ and cation effects. A summary of the discussed activation routes for $\mathrm{CO}_{2} \mathrm{RR}$ is given in Fig. 2 .

\section{Carbon-carbon bond formation}

One of the most interesting observations in the $\mathrm{CO}_{2} \mathrm{RR}$ is the formation of species with one or more carbon-carbon bonds, mostly on copper-based electrodes. Apart from copper-based catalysts, a few others, for example, NiGa, $\mathrm{PdAu}, \mathrm{NiP}$ and $\mathrm{N}$-doped carbon catalysts, produce compounds with two or more carbon atoms, but not with the same efficiency as copper ${ }^{25-28}$. There have been some remarkable achievements recently in terms of improving selectivity to $\mathrm{C}_{2}$ compounds by tuning copper structure (for example, using high-surface-area oxide-derived (OD) copper), by adjusting electrolyte composition and by employing organic films on copper ${ }^{29-32}$.

The interest in making more reduced (liquid) products from $\mathrm{CO}_{2}$ lies in the fact that they have higher energy density and economic value ${ }^{5}$. Therefore, elucidating the pathway(s) from $\mathrm{CO}_{2}$ or $\mathrm{CO}$ to 


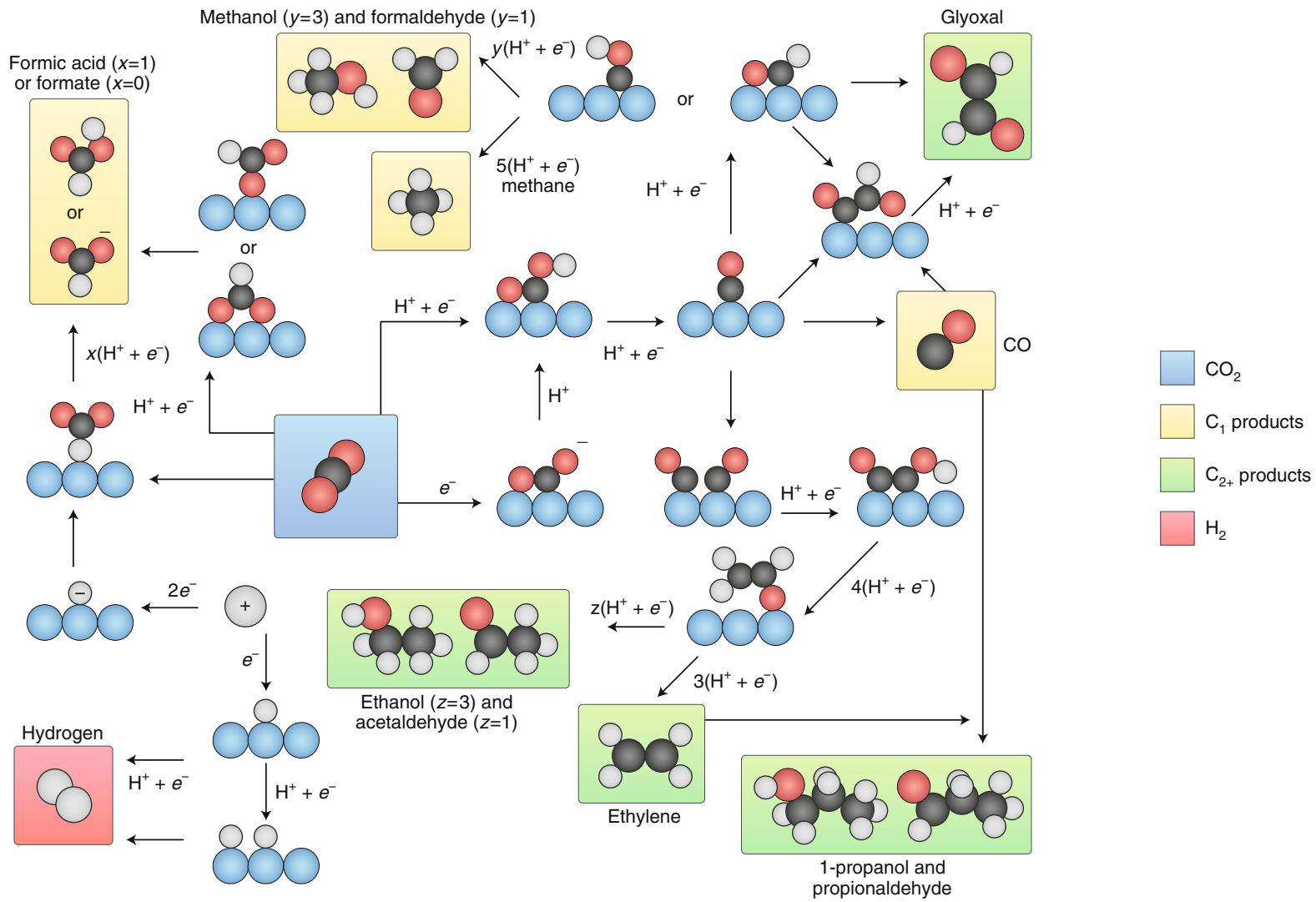

Fig. 2 | Overview of reaction pathways for $\mathrm{CO}_{2} \mathrm{RR}$ towards different products. Black spheres, carbon; red spheres, oxygen; white spheres, hydrogen; blue spheres, (metal) catalyst. The arrows indicate whether proton, electron or CPETs take place.

$\mathrm{C}_{2}$ products, of which ethylene and ethanol are the most typical examples, has been the subject of several experimental ${ }^{33-38}$ and theoretical $^{39-43}$ studies. Two separate pathways for ethylene production have been observed experimentally: a high-overpotential pathway involving a shared intermediate with the methane pathway taking place primarily on $\mathrm{Cu}(111)$, and a low-overpotential pathway taking place primarily on $\mathrm{Cu}(100)$ and which does not yield $\mathrm{C}_{1}$ products $^{36}$. The two pathways also differ in the their $\mathrm{pH}$ dependence: the ' $\mathrm{Cu}(111)$ pathway' is $\mathrm{pH}$ dependent (on the normal hydrogen electrode potential scale), whereas the ' $\mathrm{Cu}(100) \mathrm{C}_{2}$ pathway' is not. As a result, the latter pathway is favoured over the former pathway, and over hydrogen evolution in alkaline media, making the selectivity of the $\mathrm{CO}_{2}$ and $\mathrm{CO}$ reduction on copper highly sensitive to (local) $\mathrm{pH}$. Several experimental ${ }^{34,37}$ and theoretical ${ }^{39-41}$ studies have suggested a CO dimer intermediate as the key species in this $\mathrm{C}_{2}$ pathway. DFT calculations show that at more negative potentials, $\mathrm{CO}$ dimerization is disfavoured and that an alternative reaction pathway based on the coupling of ${ }^{\star} \mathrm{CO}$ and ${ }^{\star} \mathrm{CHO}$ has a lower activation energy ${ }^{41,44}$. Both experiments and DFT calculations suggest that the rate-determining step in $\mathrm{C}-\mathrm{C}$ coupling involves a decoupled proton-electron transfer $^{39}$, explaining its $\mathrm{pH}$ sensitivity. DFT calculations also show that the $\mathrm{CO}$ dimer is energetically favoured in the presence of a water layer, a local electric field and alkali cations, and that its formation energy is most favourable on $\mathrm{Cu}(100)$ (refs. ${ }^{40,42}$ ), in agreement with the experimental observation that it is a structure-sensitive and $\mathrm{pH}$-sensitive reaction. Recently, evidence has been provided for a hydrogenated $\mathrm{CO}$ dimer intermediate $(\mathrm{OCCOH})$ at low overpotentials in alkaline $\mathrm{LiOH}$ electrolyte during $\mathrm{CO}$ reduction using Fourier transform infrared spectroscopy, supported by DFT calculations ${ }^{45}$. Its formation was only observed on $\mathrm{Cu}(100)$ and not on $\mathrm{Cu}(111)$, in agreement with previous studies ${ }^{35,42}$. Interestingly, ethylene formation is favoured in $\mathrm{Cs}^{+}$-containing electrolyte, both during $\mathrm{CO}_{2}$ and $\mathrm{CO}$ reduction, although the alleged dimer intermediate was not observed in $\mathrm{CsOH}$ electrolyte, presumably because it is more reactive. Copper modified with certain organic layers also shows improved selectivity to $\mathrm{C}_{2}$ products ${ }^{29,30}$. These effects are not fully understood yet but may be related to local $\mathrm{pH}$ effects. It is well known that 'designing' an electrolyte that allows for a high nearelectrode $\mathrm{pH}$ during $\mathrm{CO}_{2} \mathrm{RR}$, such as a low buffer strength electrolyte, leads to enhanced $\mathrm{C}_{2}$ production ${ }^{46}$.

Besides ethylene, other $\mathrm{C}_{2}$ products observed during $\mathrm{CO}_{2}$ and $\mathrm{CO}$ reduction on copper are acetaldehyde and ethanol. It is normally assumed that these $\mathrm{C}_{2}$ species are formed through common intermediates on $\mathrm{Cu}(100)$ up to a selectivity-determining intermediate, the hydrogenation of which leads to acetaldehyde and subsequently ethanol, and the hydrogenolysis of which leads to ethylene ${ }^{39}$. We have proposed that ${ }^{\star} \mathrm{CH}_{2} \mathrm{CHO}$ could be such an intermediate ${ }^{47,48}$. The structure sensitivity of the further reduction of this intermediate then determines the dominant $\mathrm{C}_{2}$ product, ethylene or ethanol ${ }^{47-49}$. However, recent computational work suggested that the selectivity-determining intermediate is formed earlier in the mechanism ${ }^{44}$. An alternative pathway for ethanol formation was suggested, claiming that on $\mathrm{CuZn}$ or $\mathrm{CuAg}$ an insertion-type mechanism (CO reacting with $\mathrm{Cu}-\mathrm{CH}_{2}$ species) is operative ${ }^{50}$. We note that the $\mathrm{CO}$ dimerization mechanism can also explain why silver produces small amounts of ethanol (and no ethylene) ${ }^{47}$. Acetate is another frequently observed $\mathrm{C}_{2}$ product. It has been proposed to form as a by-product in the reaction path towards ethylene via isomerization of a three-membered ring species adsorbed on the surface $\left({ }^{*} \mathrm{OCH}_{2} \mathrm{COH}\right)$ as well as through the coupling of different adsorbed intermediates ${ }^{51,52}$. However, acetate has been shown experimentally to form in solution as a result of a base-catalysed 
disproportionation of acetaldehyde ${ }^{53}$. As far as we know, this is the only pathway that can explain why acetate can be formed also during $\mathrm{CO}$ reduction. An overview of reaction pathways towards $\mathrm{C}_{2+}$ products is shown in Fig. 2, with the important caveat that it seems probable that several competing pathways are operative, in particular at large overpotentials.

The formation of higher-order $\left(\mathrm{C}_{3+}\right)$ hydrocarbons has also been observed on copper, with a Faradaic efficiency of up to $20 \%$ on a suitable copper catalyst. ${ }^{54}$ The main $\mathrm{C}_{3}$ products are propanol and propionaldehyde, with small amounts of hydroxyacetone, acetone and allyl alcohol ${ }^{55}$. The elementary steps through which these $\mathrm{C}_{3}$ products are formed have not been well studied yet. $\mathrm{C}-\mathrm{C}$ coupling between $\mathrm{CO}$ and $\mathrm{C}_{2} \mathrm{H}_{4}$ precursors has been reported to form $n$-propanol on agglomerates of OD copper nanocrystals ${ }^{56}$. For this reaction, defect sites were proposed to be the active sites. Moreover, polymerization of adsorbed carbon-based species has been proposed as a mechanism for the formation of higher-order hydrocarbons on bimetallic PdAu electrodes ${ }^{26}$. Although CO insertion-type reaction steps seem likely, there is still a lack of mechanistic work on the electrochemical formation of $\mathrm{C}_{3+}$ hydrocarbons.

\section{Reaction and process conditions}

The nature of the solvent (aqueous or non-aqueous), $\mathrm{pH}$, the identity of ionic species, buffering strength and the exact mass-transport conditions all influence the activity and selectivity of $\mathrm{CO}_{2} \mathrm{RR}^{57}$. However, the interpretation of the individual effects remains poorly understood, and only recently systematic work was performed to elucidate and separate these effects. The importance of reaction and process conditions also implies the importance of proper standard protocols, as discussed recently ${ }^{58}$.

The $\mathrm{CO}_{2} / \mathrm{HCO}_{3}{ }^{-}, \mathrm{H}_{2} \mathrm{CO}_{3} / \mathrm{HCO}_{3}{ }^{-}$and $\mathrm{HCO}_{3}{ }^{-} / \mathrm{CO}_{3}{ }^{2-}$ equilibria in water are sensitive to (bulk) $\mathrm{pH}$, electrolyte composition and buffer capacity, which leads to different concentrations of carbonaceous species in solution (Fig. 3a) ${ }^{59}$. This has led to some controversy about the real active form of $\mathrm{CO}_{2}$ during $\mathrm{CO}_{2} \mathrm{RR}$. Most authors acknowledge now that dissolved $\mathrm{CO}_{2}$ is the active species, though bicarbonate has also been suggested as the active species, especially towards formate ${ }^{60-62}$. Enhanced $\mathrm{CO}_{2} \mathrm{RR}$ activity in bicarbonate electrolyte, compared with other electrolytes under similar conditions, has been proposed to be associated with the formation of a bicarbonate- $\mathrm{CO}_{2}$ complex. Such a complex is a primary carbon source during $\mathrm{CO}_{2} \mathrm{RR}$, leading to an increase in $\mathrm{CO}_{2}$ concentration in the vicinity of the electrode ${ }^{63}$. In situ Fourier transform infrared experiments using isotope labelling have confirmed this role of bicarbonate ${ }^{64}$. However, it was concluded that bicarbonate is not explicitly involved as an active species in the rate-limiting step of CO formation on gold, but rather that bicarbonate is a proton donor in a reaction step after the rate-limiting step ${ }^{65}$. The authors also conclude that the sluggish kinetics of the reaction converting bicarbonate into $\mathrm{CO}_{2}$ must be considered. More generally, buffering anions in the electrolyte can donate a proton more effectively than water, or compared with other anions, which leads to an anion effect for the HER and formation of $\mathrm{CH}_{4}$, but not for $\mathrm{CO}_{2} \mathrm{RR}$ towards $\mathrm{CO}, \mathrm{HCOO}^{-}$, $\mathrm{C}_{2} \mathrm{H}_{4}$ and ethanol ${ }^{66}$.

As soon as Faradaic currents are flowing, the importance of the local $\mathrm{pH}$ and local concentration of carbonaceous species must be taken into account ${ }^{46,57,67,68}$. The interpretation of experimental data must invoke the presence of local concentration gradients ${ }^{68}$. During $\mathrm{CO}_{2} \mathrm{RR}$, a more alkaline $\mathrm{pH}$ than the bulk $\mathrm{pH}$ is manifested in the vicinity of the electrode, as a result of hydroxide formation from both the HER and $\mathrm{CO}_{2} \mathrm{RR}$. This local alkaline $\mathrm{pH}$ is the result of masstransport limitations $\mathrm{s}^{57}$. This local $\mathrm{pH}$ change is proportional to the current density ${ }^{69}$, but also depends on the nature and buffer capacity of the electrolyte, and on the morphology of the electrode. Therefore, modelling concentration gradients near the electrode surface during $\mathrm{CO}_{2} \mathrm{RR}$ is crucial to understand the overall reactive system. Recent model calculations of $\mathrm{pH}$ gradients and $\mathrm{CO}_{2}$ transport within a fixed boundary layer for different electrolytes showed the importance of buffer identity, buffer capacity, buffer $\mathrm{p} K_{\mathrm{a}}$ and $\mathrm{CO}_{2}$ pressure on the reaction kinetics, as well as the importance of the buffer kinetics ${ }^{70}$. We expect that the combination of such models with surface kinetics models will become increasingly important in designing reactive electrochemical three-dimensional interphases as shown in recent work on $\mathrm{pH}$ effects to explain $\mathrm{C}_{1}$ versus $\mathrm{C}_{2}$ selectivity ${ }^{71}$.

Since the (local) pH near the electrode has such an important role in some of the crucial steps in $\mathrm{CO}_{2} \mathrm{RR}$ (see the previous sections), reactivity and selectivity can be tuned by the electrolyte composition $^{46,67,70}$. A prime example of this effect happens on $\mathrm{Cu}$ electrocatalysts, for which the selectivity towards ethylene can be enhanced by lowering the buffer capacity, thereby favouring a higher local $\mathrm{pH}^{46,72}$. In addition, the selectivity can be steered towards ethylene by increasing the $\mathrm{CO}_{2}$ pressure, leading to enhanced local CO concentration and a higher ${ }^{\star} \mathrm{CO}$ coverage ${ }^{71}$.

Another parameter influencing the local $\mathrm{pH}$ and consequently the product distribution of $\mathrm{CO}_{2} \mathrm{RR}$ is the electrode morphology (Fig. 3c). It has been shown that the increased mesoporosity of silver and gold catalysts alters the selectivity in favour of $\mathrm{CO}_{2}$-to- $\mathrm{CO}$ conversion, compared with $\mathrm{H}_{2}$ evolution, which is attributed to enhanced local $\mathrm{pH}$ gradients in highly mesoporous films ${ }^{73,74}$. These trends were corroborated by comparison to rotating (cone) electrode experiments, showing that enhanced mass transport is advantageous to hydrogen evolution, but has a neutral or inhibitive effect on $\mathrm{CO}_{2} \mathrm{RR}$. Using rotating copper cylinder electrodes, it was shown that the $\mathrm{CO}_{2} \mathrm{RR}$ activity decreases with higher rotation rate, related to a change in selectivity from $\mathrm{CH}_{4}$ to $\mathrm{CO}$ as $\mathrm{CO}$ is more readily transported away with enhanced convection ${ }^{75}$. Rotating copper disk electrode experiments in mildly acidic media revealed that water reduction is the HER pathway in competition with $\mathrm{CO}_{2} \mathrm{RR}$, instead of proton reduction ${ }^{76}$. The suppression of water reduction on copper was suggested to be the result of ${ }^{\star} \mathrm{CO}$ on the copper electrode, which is more pronounced at low rotation rates (as CO does not diffuse away). Note that one should be careful with the interpretation and comparison of experimental data of high-surface-area electrocatalysts on the reversible hydrogen electrode (RHE) scale, since the local $\mathrm{pH}$ may be significantly different compared with the bulk $\mathrm{pH}$, leading to deviations on the RHE scale ${ }^{58}$.

Another consequence of a local alkaline $\mathrm{pH}$ as a result of the concomitant HER during $\mathrm{CO}_{2} \mathrm{RR}$ is the occurrence of homogeneously catalysed chemical reactions, which may seriously affect the overall product spectrum ${ }^{53,77}$. Cannizzaro-type reactions can take place during $\mathrm{CO}_{2} \mathrm{RR}$, in which intermediate aldehydes disproportionate into their corresponding carboxylic acid and primary alcohol $^{53}$. This phenomenon is enhanced by the alkaline $\mathrm{pH}$ near the electrode, and is therefore more important in poorly buffered or unbuffered electrolytes, and on electrodes with high porosity. The obtained products (acids and alcohols) should be distinguished from direct $\mathrm{CO}_{2} \mathrm{RR}$ products.

The nature of the electrolyte cations and anions has been shown to have a significant effect on the activity and selectivity of the $\mathrm{CO}_{2} \mathrm{RR}$. Larger cations usually lead to higher $\mathrm{CO}_{2} \mathrm{RR}$ rates and a higher $\mathrm{C}_{2} / \mathrm{C}_{1}$ ratio (on copper electrodes) ${ }^{78-80}$. A cation hydrolysis effect has been suggested to lead to an enhanced buffering near the electrode for larger cations, which in turn increases the local concentration of dissolved $\mathrm{CO}_{2}$ (refs. ${ }^{79,81}$ ). An alternative rationalization of the cation effect is the lesser stabilization of $2{ }^{*} \mathrm{CO}$ compared with ${ }^{\star} \mathrm{OCCO}$ and ${ }^{\star} \mathrm{OCCOH}$ (refs. ${ }^{16,32,82}$ ). The onset potential for ethylene depends on the cation nature, while for methane no correlation with cation size was found ${ }^{82}$.

The effect of anions on the $\mathrm{CO}_{2} \mathrm{RR}$ has been investigated, although less extensively compared with cations, and these studies generally deal with halide effects on copper ${ }^{83-87}$. Anion effects are generally explained in terms of halide adsorption on the catalyst 


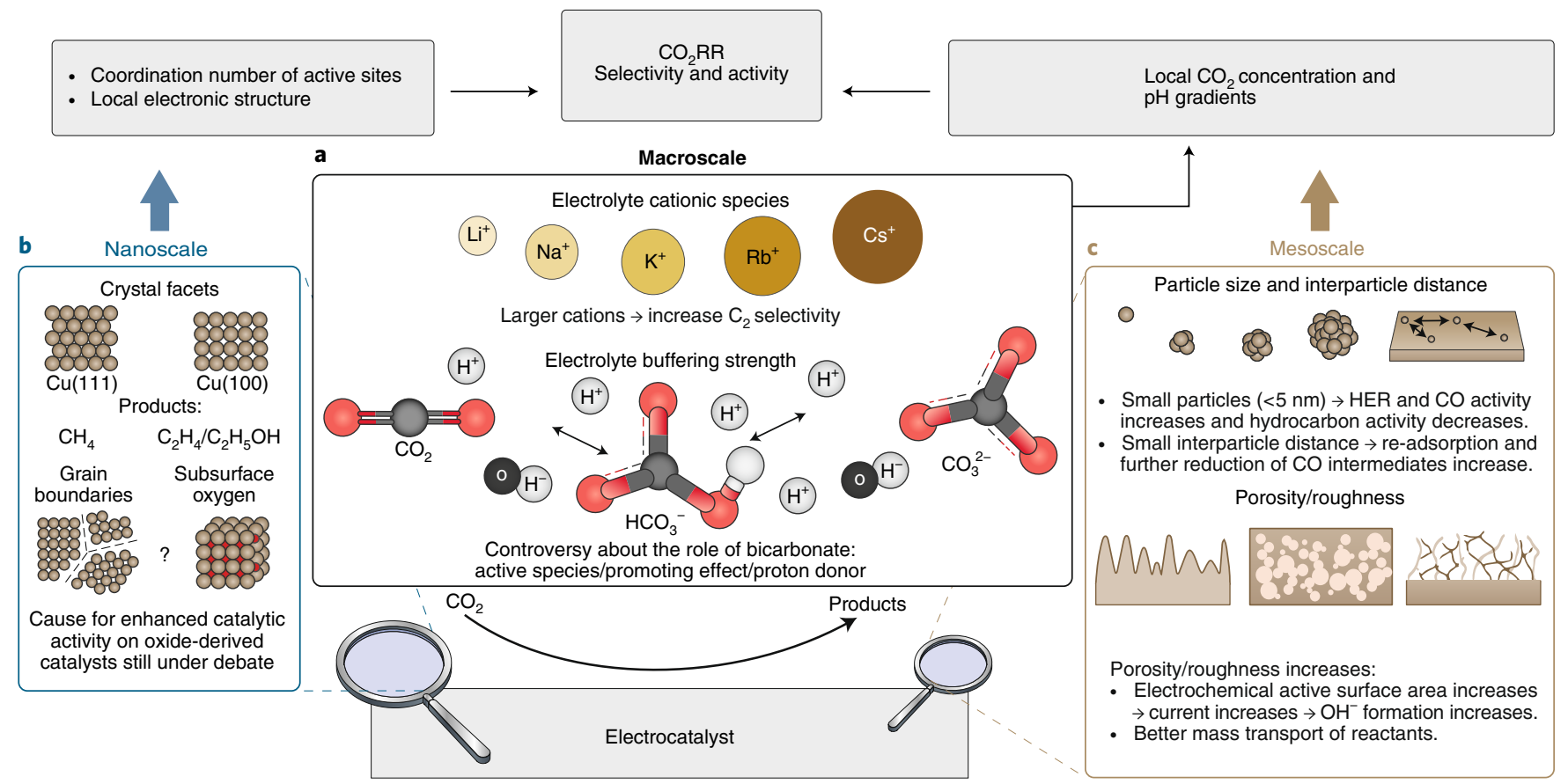

Fig. 3 | Schematic of the different length scales involved in the understanding of $\mathrm{CO}_{2} \mathrm{RR}$ and of the influence of relevant parameters. a, Macroscale: electrolyte composition and buffering strength. b, Nanoscale: crystal facets, grain boundaries or subsurface oxygen. c, Mesoscale: influence of particle size, interparticle distance and porosity.

surface, altering the electronic structure and subsequently the $\mathrm{CO}_{2} \mathrm{RR}$ activity and selectivity, which are also dependent on the halide size and concentration ${ }^{85}$. Moreover, specifically adsorbed halide anions can suppress proton adsorption, favouring $\mathrm{CO}_{2} \mathrm{RR}$ with respect to the $\mathrm{HER}^{84}$. Halide ions can also aid in the formation of well-defined copper nanocrystals by nanostructuring of the copper catalyst ${ }^{86}$. As mentioned before, buffering anions have also been shown to have a role in the formation of $\mathrm{H}_{2}$ and $\mathrm{CH}_{4}$ (ref. ${ }^{66}$ ).

\section{Electrode morphology and (sub)surface atoms}

The effect of electrode morphology on $\mathrm{CO}_{2} \mathrm{RR}$ performance should be understood on different length scales, a schematic illustration of which is shown in Fig. 3. On one end of the spectrum is the atomiclevel structure of the surface, which can be studied with different single-crystal surfaces (Fig. 3b) ${ }^{33}$. Nanostructured ${ }^{88-92}$ and mesostructured ${ }^{74,93-96}$ catalysts and OD electrodes ${ }^{97-105}$ have been shown to influence the $\mathrm{CO}_{2} \mathrm{RR}$ activity and selectivity through the variation of the coordination number of the active sites, local electronic structure by the presence of subsurface oxygen, catalyst particle size and readsorption of intermediates by the interparticle distance. The electrode's mesostructure also substantially affects the mass transport of reactants (Fig. 3c). Rough or high-surface-area surfaces, such as OD copper electrodes, exhibit improved hydrocarbon selectivity compared with smooth surfaces. This is typically attributed to the increased population of undercoordinated $\operatorname{sites}^{88}$, but as discussed in the previous section, high-surface-area mesoporous catalysts also tend to suppress hydrogen evolution due to the poorer mass transport in porous systems. Cubic-shaped copper nanocrystals steer the selectivity towards ethylene with respect to methane ${ }^{89,90}$, in agreement with the observation that $\mathrm{Cu}(100)$ facets favour $\mathrm{C}-\mathrm{C}$ coupling.

A particle size effect of $\mathrm{Cu}$ nanoparticles has been reported ${ }^{92}$, showing that the activity for $\mathrm{H}_{2}$ and $\mathrm{CO}$ is increased with decreasing particle size $(<5 \mathrm{~nm})$, while the selectivity towards hydrocarbons is decreased. This observation was attributed to a higher number of undercoordinated sites (coordination number $<8$ ), which promote HER and $\mathrm{CO}$ formation due to stronger chemisorption of ${ }^{\star} \mathrm{CO}$.
Paradoxically, ${ }^{\star} \mathrm{CO}$ is difficult to be reduced further, which was ascribed to lower surface mobility. Particle-size effects of $\mathrm{CO}_{2} \mathrm{RR}$ activity on gold nanoparticles have also been observed, leading to a drastic increase in the $\mathrm{H}_{2} / \mathrm{CO}$ ratio for very small nanoparticles, which was attributed to the increase of specific edge sites that enhance ${ }^{*} \mathrm{COOH}$ stabilization with respect to ${ }^{\star} \mathrm{H}$ stabilization ${ }^{106,107}$.

Investigation of mesoscale phenomena has also demonstrated the effects of particle size and particle distance on the product selectivity for well-defined $\mathrm{Cu}$ catalysts ${ }^{95}$. Re-adsorption of CO intermediates, followed by their further reduction, was found to be associated with small interparticle distance and larger nanoparticle sizes, whereas small nanoparticles suffer from active-site poisoning by CO.

Various authors have suggested pre-treatments of (metallic) catalysts to enhance their activity for $\mathrm{CO}_{2} \mathrm{RR}$. Increased efficiency, selectivity and stability of $\mathrm{CO}_{2} \mathrm{RR}$ were revealed on OD electrocatalysts, which were obtained by reducing metal-oxide films $\mathrm{s}^{97,103}$. Improved $\mathrm{CO}_{2} \mathrm{RR}$ activity has been reported for $\mathrm{OD}-\mathrm{Au}, \mathrm{OD}-\mathrm{Cu}$, $\mathrm{OD}-\mathrm{Ag}$ and $\mathrm{OD}-\mathrm{Pb}^{97,98,103-105}$. Many papers have been published regarding $\mathrm{CO}_{2} / \mathrm{CO}$ reduction on OD-Cu electrodes ${ }^{99-102}$, but the key factors responsible for the improved selectivity and activity of OD electrocatalysts are still debated. In this respect, increased stabilization of the $\mathrm{CO}_{2}$ anionic adsorbate $\left(\mathrm{CO}_{2}{ }^{--}\right)$by grain boundaries as well as the presence of (sub)surface oxygen have been reported to play a role, although no consensus has been reached yet ${ }^{108-110}$.

On OD-Au, a high selectivity to $\mathrm{CO}$ at low overpotential was found, which was ascribed to improved stabilization of $\mathrm{CO}_{2}{ }^{--}$on $\mathrm{OD}-\mathrm{Au}$ compared with polycrystalline $\mathrm{Au}^{103}$. Grain boundaries have also been shown to have enhanced activity for $\mathrm{CO}_{2} \mathrm{RR}$ activity on $\mathrm{Au}^{111}$. Similar conclusions have been drawn regarding $\mathrm{CO}$ production on $\mathrm{OD}-\mathrm{Cu}^{100}$. In addition, on oxide-derived copper the enhanced activity and stability compared with polycrystalline copper depend on the initial thickness of the $\mathrm{Cu}_{2} \mathrm{O}$ layers and is not significant for thin films $(<3 \mu \mathrm{m})^{97,101}$. Remarkable improvements of the selectivity towards ethanol, acetate and $n$-propanol for $\mathrm{CO}$ reduction on similar OD electrodes have been reported ${ }^{102}$, with the improved selectivity attributed to grain boundaries. 
Oxygen plasma activation is another form of pretreatment that yields significantly enhanced $\mathrm{CO}_{2} \mathrm{RR}$ activity ${ }^{112,113}$. The treatment is suggested to yield highly defect-rich surfaces. In the case of plasma-treated copper, subsurface oxygen and the presence of $\mathrm{Cu}^{+}$have been suggested as key for the reactivity and selectivity enhancement. Following up on the potential involvement of subsurface oxygen, it was proposed that it modifies the electrocatalyst's electronic structure by reducing $\sigma$-repulsion, leading to increased ${ }^{\star} \mathrm{CO}$ binding energies, primarily near grain boundaries ${ }^{110}$. Another explanation is that subsurface oxygen facilitates neutral and charged copper sites at the surface, leading to chemisorbed $\mathrm{CO}_{2}$ in presence of water and consequently enhanced $\mathrm{CO}_{2} \mathrm{RR}$ activity ${ }^{114}$. DFT calculations have indeed shown that interstitial oxygen species are stable at the $\mathrm{Cu}(111)$ subsurface, contrary to $\mathrm{Cu}(211)$, and are capable of improving $\mathrm{CO}_{2}$ binding to the surface ${ }^{115}$. In contrast, recent DFT-based work concluded that diffusion barriers for subsurface oxygen are low and hence it is unlikely that subsurface oxygen is stable during the negative potentials at which $\mathrm{CO}_{2} \mathrm{RR}$ takes place ${ }^{116}$. From experiments employing ${ }^{18} \mathrm{O}$ labelling, it was also concluded that residual (subsurface) oxides should be unstable under $\mathrm{CO}_{2} \mathrm{RR}$ conditions $^{117}$. Moreover, theoretical work has shown that subsurface oxygen is not a prerequisite for $\mathrm{CO}_{2}$ adsorption ${ }^{118}$ and that coordinatively unsaturated $\mathrm{Cu}$ atoms facilitate $\mathrm{C}-\mathrm{C}$ bond formation ${ }^{42,119,120}$.

When $\mathrm{Cu}_{x} \mathrm{O}$ is used directly for $\mathrm{CO}_{2} \mathrm{RR}$, methanol ${ }^{121,122}$, ethanol ${ }^{123,124}$ and ethylene $e^{123}$ are observed as major products. It is often assumed that during $\mathrm{CO}_{2} \mathrm{RR}$, the $\mathrm{Cu}_{x} \mathrm{O}$ electrocatalyst should be completely converted to metallic $\mathrm{Cu}$. However, a residual oxide layer was shown to remain present on the surface during $\mathrm{CO}_{2} \mathrm{RR}$ and the surface oxide and OD metallic layer were proposed as key reaction sites for catalysis ${ }^{125}$. The formation of $\mathrm{C}_{3}-\mathrm{C}_{4}$ products was also reported, supposedly due to a synergistic effect between $\mathrm{Cu}_{2} \mathrm{O}$ and $\mathrm{Cl}$ adsorption, which resulted in a higher population of $\mathrm{Cu}^{+}$species $^{126}$. In an interesting pulse voltammetry experiment, it was shown that a freshly oxidized copper electrode obtained by repeated anodic pulsing has enhanced selectivity towards oxygenated hydrocarbons ${ }^{127}$.

In conclusion, the exact nature of the active sites of $\mathrm{OD} \mathrm{CO} \mathrm{CO}_{2} \mathrm{RR}$ catalysts remains controversial and as yet unresolved. Apart from chemical or materials-related aspects such as those discussed, some researchers have argued that the activity and selectivity follow rather simple and consistent trends with current and potential ${ }^{128}$. Reliable methods to measure accurately the electrochemically active surface area ${ }^{129}$ of copper electrodes (beyond surface capacitance measurements, which may sometimes be inaccurate ${ }^{130}$ ) will be paramount in clarifying such effective-surface-area effects.

\section{In situ spectroscopic investigation of $\mathrm{CO}_{2}$ reduction}

There has been a number of recent in situ (or operando) spectroscopy studies of the $\mathrm{CO}_{2} \mathrm{RR}$, based on (surface-enhanced) infrared adsorption spectroscopy ((SE)IRAS) or surface-enhanced Raman spectroscopy (SERS). Such studies typically aim at identifying surface-adsorbed intermediates, and their observation or evolution as a function of parameters such as electrode potential, electrode surface and electrolyte composition.

SEIRAS was utilized to measure adsorption profiles of $\mathrm{CO}$ on copper electrodes ${ }^{38} .{ }^{\star} \mathrm{CO}$ was observed at potentials $<-0.60 \mathrm{~V}$ versus SHE, with a maximum coverage at ca. $-1.2 \mathrm{~V}$ versus SHE, independent of $\mathrm{pH}$. ${ }^{*} \mathrm{CO}$ was observed to be in dynamic equilibrium with $\mathrm{CO}$ in solution, and ${ }^{\star} \mathrm{CO}$ is assumed to serve as a pool of intermediates for further reduction. In addition to ${ }^{\star} \mathrm{CO}$, other researchers also observed ${ }^{\star} \mathrm{H}$ using SEIRAS, and demonstrated that the two species show an asymmetric blocking effect: ${ }^{\star} \mathrm{H}$ can displace ${ }^{\star} \mathrm{CO}$, but ${ }^{\star} \mathrm{CO}$ cannot displace ${ }^{\star} \mathrm{H}$ (ref. ${ }^{131}$ ). Using isotope labelling and in situ SEIRAS, it was shown that carbonate is an important source of $\mathrm{CO}_{2}$ near the electrode surface, implying a dynamic equilibrium between bicarbonate and dissolved $\mathrm{CO}_{2}$ (ref. ${ }^{64}$ ). The authors also observed (very) weak bands possibly due to other surface-adsorbed intermediates such as ${ }^{\star} \mathrm{CHO}$ or ${ }^{\star} \mathrm{COOH}$. Using both SEIRAS and SERS, the potential dependence of two different ${ }^{\star} \mathrm{CO}$ bands was analysed, from which it was concluded that the copper surface undergoes a reversible morphological change during potential cycling ${ }^{132}$. The role of metastable surface oxides for $\mathrm{CO}_{2} \mathrm{RR}$ was investigated on tin, indium, lead and bismuth electrodes, by means of attenuated total reflectance SEIRAS ${ }^{133}$. The results indicate the competition between $\mathrm{CO}_{2}$ and $\mathrm{H}^{+}$for reaction sites (oxidized or metallic), depending on the nature of the electrode. Regarding the formation of $\mathrm{C}_{2}$ species, our group used in situ IRAS on copper single-crystal electrodes to provide evidence for a (hydrogenated) dimer intermediate $\left({ }^{*} \mathrm{COCOH}\right)$ with two different $\mathrm{C}-\mathrm{O}$ stretching frequencies on $\mathrm{Cu}(100)$ in alkaline media, coinciding with the conditions under which $\mathrm{CO}$ reduction on copper yields $\mathrm{C}_{2}$ products such as ethyl$e^{45}{ }^{45}$. A recent theoretical work attributes those frequencies to different intermediates ${ }^{134}$.

Following the previous discussion on the importance of local $\mathrm{pH}$, in situ SEIRAS was used to probe the local $\mathrm{pH}$ by comparing the band intensities of $\mathrm{HCO}_{3}{ }^{-}$and $\mathrm{CO}_{2}$, showing that the local $\mathrm{pH}$ near gold electrodes depends on the nature of the electrolyte cation $^{135}$. SEIRAS was used on gold electrodes to study the production of $\mathrm{CO}$ (by adsorbing the $\mathrm{CO}$ generated at higher potentials) and showed the importance of $\mathrm{HCO}_{3}{ }^{-}$in effectively increasing the $\mathrm{CO}_{2}$ concentration $^{63}$, as later confirmed for copper electrodes ${ }^{64}$ (see previous paragraph).

Using in situ IRAS and SERS, a high sensitivity of $\mathrm{CO}_{2} \mathrm{RR}$ in non-aqueous solvents to the presence of residual water has been observed ${ }^{136}$. In non-dry conditions, ${ }^{*} \mathrm{CO}$ is the major product at low overpotentials, and (bi)carbonates are formed at $\mathrm{Cu}, \mathrm{Pt}$, $\mathrm{Au}, \mathrm{Pd}$ and $\mathrm{Ag}$ electrodes from the chemical reaction of $\mathrm{CO}_{2}$ with $\mathrm{OH}^{-}$species generated by water reduction. As a consequence, (bi) carbonate formation was found to be related to the water content. The formation of oxalate was observed only for $\mathrm{Pb}$ electrodes at high overpotentials.

As is customary with steady-state spectroscopy, identifying (lowcoverage) reactive intermediates is difficult, and there is little consistent and widespread evidence for carbon-based intermediates other than ${ }^{\star} \mathrm{CO}$. Hyphenation of in situ spectroscopy with online product identification techniques would be a next instrumental challenge in furthering our understanding of $\mathrm{CO}_{2} \mathrm{RR}$, as it would enable the establishment of direct relationships between observed adsorbed intermediates and product selectivity. Moreover, in situ synchrotron-based techniques such as X-ray absorption spectroscopy ${ }^{112,137}$ and ambient-pressure X-ray photoelectron spectroscopy ${ }^{110}$ are promising in understanding interfacial electrochemistry, and have recently been employed to gain insight into the chemical state of the active $(\mathrm{Cu})$ species on $\mathrm{OD}$ catalysts for $\mathrm{CO}_{2} \mathrm{RR}$. An overview of typical spectroelectrochemical techniques used for the understanding of $\mathrm{CO}_{2} \mathrm{RR}$ is depicted in Fig. 4. For more elaborate reviews of in situ spectroelectrochemical techniques applied to $\mathrm{CO}_{2} \mathrm{RR}$ research, the reader is referred to specialized recent reviews ${ }^{138-140}$.

\section{Computational approaches for $\mathrm{CO}_{2}$ reduction}

DFT calculations applied to the electrode/electrolyte interface are a far from simple endeavour, but much progress has been made in improving models. A recent detailed review of the computational modelling of $\mathrm{CO}_{2}$ and $\mathrm{CO}$ reduction to (oxygenated) hydrocarbons can be found elsewhere ${ }^{141}$. Here we limit ourselves to the foundations, recent advances and key scientific challenges of descriptorbased analyses, which are the most widespread computational approaches for $\mathrm{CO}_{2} \mathrm{RR}$. An overview of the fundamentals of the method is depicted in Fig. 5.

The computational hydrogen electrode (CHE) is widely employed in computational electrocatalysis ${ }^{142}$. In combination with DFTcalculated adsorption energies of the intermediates (Fig. 5a), one 
a

X-ray absorption spectroscopy and X-ray photoelectron spectroscopy
- Insight in chemical state of active species

- Insight in chemical state of active species

- Influence of residual oxygen

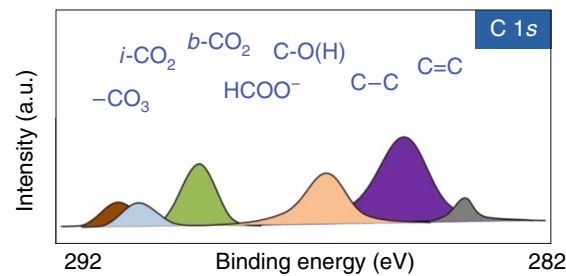

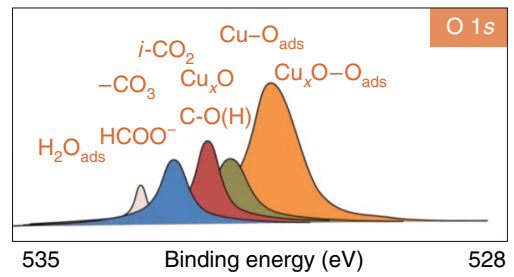

SERS and SEIRAS

b

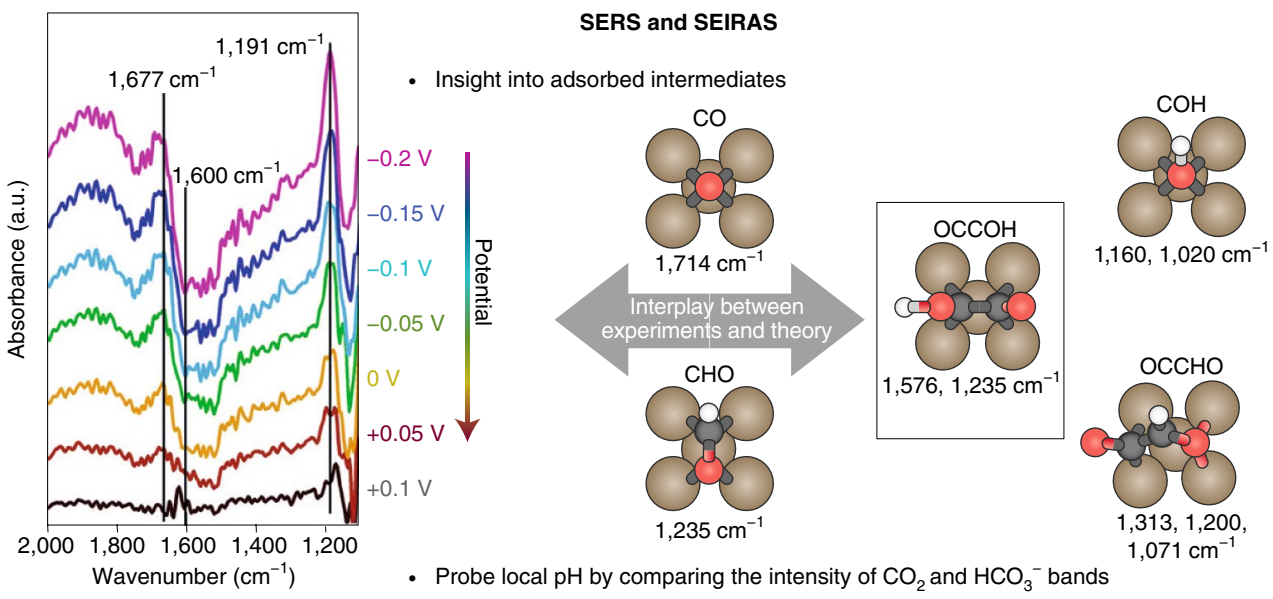

Fig. 4 | In situ spectroelectrochemical techniques used in the understanding of $\mathrm{CO}_{2} \mathbf{R R}$. a, X-ray absorption spectroscopy and (ambient-pressure) X-ray photoelectron spectroscopy to gain insight into the active species. b, SERS and (SE)IRAS for understanding the mechanism by observation of adsorbed intermediates (data reproduced from ref. ${ }^{45}$ for the detection of $\mathrm{OCCOH}$ at low overpotentials during $\mathrm{CORR}$ in $\mathrm{LiOH}$ solutions), or to probe the local pH. Figure adapted from ref. ${ }^{45}$, Wiley.

can gain insight into the coverage of surface species at specific $\mathrm{pH}$ and potentials by means of surface Pourbaix diagrams (Fig. 5b) ${ }^{143}$, and possible reaction pathways and the potentials at which the redox reactions take place (Fig. $5 \mathrm{c})^{39,144,145}$. Studies combining these approaches can also be found in the $\mathrm{CO}_{2} \mathrm{RR}$ literature ${ }^{146,147}$.

CHE-based models typically assume CPET steps, and are therefore not straightforwardly applicable for reaction pathways where decoupled proton-electron transfer steps are involved. Sequential proton-electron transfer (SPET) steps have been observed on molecular, oxide and metal electrocatalysts, and manifest experimentally through $\mathrm{pH}$ effects on the RHE scale $\mathrm{e}^{6,148,149}$. Recently, a simple methodology was introduced that allows the transition between coupled and decoupled proton-electron transfer pathways to be predicted ${ }^{12}$ based on first-principles calculations of acid-base equilibrium constants. Using this methodology, the experimental $\mathrm{pH}$ dependence of $\mathrm{CO}_{2} \mathrm{RR}$ on immobilized cobalt protoporphyrins was rationalized, as discussed in the section about initial activation of $\mathrm{CO}_{2}$ (ref. ${ }^{13}$ ).

The presence of linear correlations between adsorption energies of similar adsorbates, known as scaling relations (Fig. $5 \mathrm{~d})^{150}$, reduces the complexity of DFT-based catalytic models and facilitates the simultaneous analysis of numerous materials through Sabatier-type activity plots (Fig. 5e). Such correlations per se do not carry information on the effect of applied potential, so it might be advisable to ascertain first the relevant surface coverage using surface Pourbaix diagrams ${ }^{146,147}$. Scaling relations might pose extra constraints for finding optimal electrocatalysts with low overpotentials, and have therefore been extensively studied ${ }^{151-153}$. Recent efforts were directed to break or circumvent scaling relations, especially between the intermediates of the electrocatalytic oxygen evolution and reduction reactions and $\mathrm{CO}_{2} \mathrm{RR}^{42,154,155}$. The strategy is clear, although difficult to implement experimentally: one of the problematic intermediates needs to be significantly stabilized with respect to the other(s). For instance, the preference of $\mathrm{Cu}(100)$ for the production of ethylene and ethanol over methane has been explained on the basis of the breaking of scaling relations between ${ }^{\star} \mathrm{CO}$ and ${ }^{\star} \mathrm{CO}$ dimers $\left({ }^{\star} \mathrm{C}_{2} \mathrm{O}_{2}\right)$ on that facet due to strong ensemble effects for the $\mathrm{CO}$ dimerization step (Fig. $5 \mathrm{~d}$, top) ${ }^{42}$. Another example is the nearly reversible reduction of $\mathrm{CO}_{2}$ to $\mathrm{CO}$ on $\mathrm{CODH}$ enzymes, the active site of which does not obey the scaling relationship between ${ }^{\star} \mathrm{CO}$ and ${ }^{\star} \mathrm{COOH}^{156}$. Furthermore, several strategies for breaking scaling relations in $\mathrm{CO}_{2} \mathrm{RR}$ have been discussed: alloying, tethering, addition of promoters, creation of low-coordination sites and introduction of p-block dopants or oxophilic sites. ${ }^{145,157}$ Other ways to depart from scaling relations are altering adsorbate solvation via modification of the electrolyte composition/dielectric constant ${ }^{154,158}$, anchoring active ligands on the surface or at the active sites ${ }^{159}$, strain effects ${ }^{160}$ and the study of transition-metal-free electrocatalysts ${ }^{147}$.

However, a word of warning is provided here. Recent studies have pointed out that breaking scaling relations is a necessary yet insufficient condition for the optimization of electrocatalysts. In other words, materials that break scaling relations are not necessarily active, while high activities can be achieved by materials that do not break them ${ }^{153}$. Furthermore, scaling-relation-based volcano plots for $\mathrm{CO}_{2} \mathrm{RR}$ assume that a single mechanism is operative on all materials and facets (Fig. $5 c, e)^{145,157}$. However, recent studies have shown that the $\mathrm{CO}_{2} \mathrm{RR}$ reaction mechanism is both material and structure sensitive. For instance, while it is typically assumed that ${ }^{\star} \mathrm{CO}$ hydrogenation leads only to ${ }^{\star} \mathrm{CHO}$, structure-sensitive scaling relations show that it may lead to ${ }^{\star} \mathrm{COH},{ }^{\star} \mathrm{CHO}$, or both, depending 
a Assessment of free energies of adsorption

\begin{tabular}{ll} 
Binding energies in vacuum: & $\Delta E_{\mathrm{ADS}}$ \\
+ zero point energies: & $\Delta \mathrm{ZPE}$ \\
+ entropy corrections: & $-T \Delta S$ \\
+ solvation corrections: & $\Delta E_{\mathrm{sol}}$ \\
\hline Approximate free energies & $\Delta G_{\mathrm{ADS}}$
\end{tabular}

C Free-energy diagrams and reaction pathways

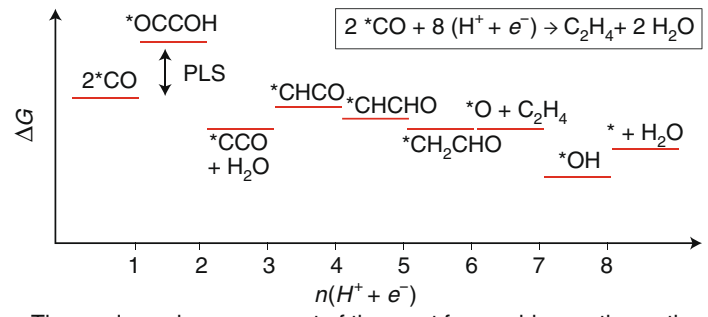

Thermodynamic assessment of the most favourable reaction pathway. The potential-limiting step (PLS) has the largest $(>0)$ reaction energy.

e Sabatier-type volcano plots

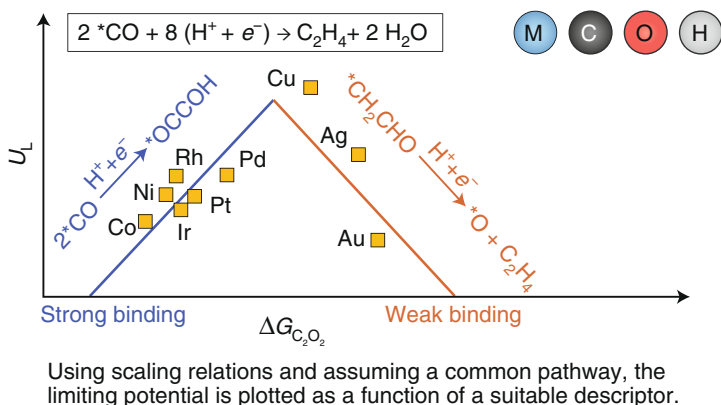

b Surface Pourbaix diagrams

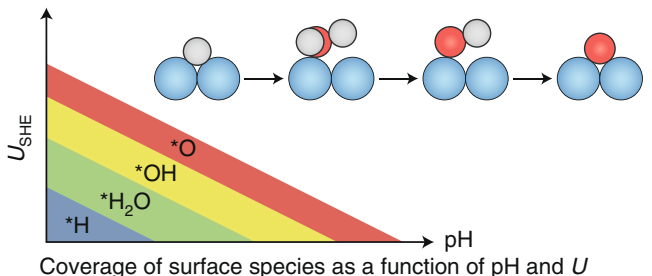

d Adsorption-energy scaling relations

(1) Fulfilment for the same facet of different metals

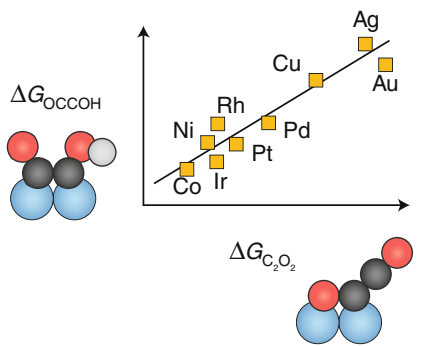

(2) Fulfilment and breakage for different sites of a given metal

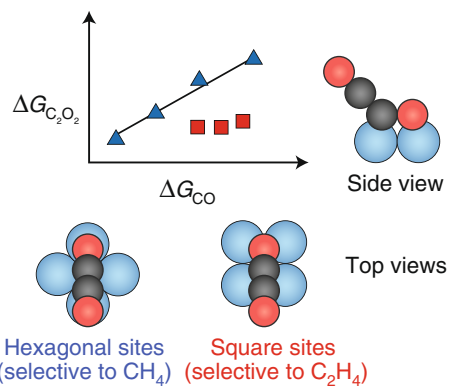

Fig. 5 | Fundamentals of descriptor-based analyses for $\mathrm{CO}_{2} \mathrm{RR}$. $\mathbf{a}$, Assessment of free energies of adsorption starting from DFT calculations and adding zero-point energy, entropy and solvation corrections. b, Surface Pourbaix diagrams, which predict the thermodynamically most stable adsorbed species and their coverage as a function of $\mathrm{pH}$ and the potential versus the standard hydrogen electrode $\left(U_{\mathrm{SHE}}\right)$. c, Free-energy diagrams and most favourable reaction pathways for $\mathrm{CORR}$ to $\mathrm{C}_{2} \mathrm{H}_{4}$ on $\mathrm{Cu}(100)$. d, Various types of scaling relations between adsorption energies. e, Sabatier-type volcano plots based on scaling relations and the most favourable reaction pathway found in $\mathbf{c}$ for CORR to $\mathrm{C}_{2} \mathrm{H}_{4}$ on (100) surfaces of transition metals. The colour code is provided as an inset and $\mathrm{M}$ is a surface metal atom. Panels adapted from: c, ref. ${ }^{39}$, Wiley; $\mathbf{d}$, ref. ${ }^{42}$, American Chemical Society; $\mathbf{d}, \mathbf{e}$, ref. ${ }^{47}$, American Chemical Society.

on the active sites (Fig. 6a) ${ }^{161}$. Thus, such assumptions may sometimes lead to erroneous design principles.

CHE-based models do not generally incorporate reaction barriers, which is another important topic under study in $\mathrm{CO}_{2}$ and $\mathrm{CO}$ electroreduction models (Fig. 6b) ${ }^{162-164}$. An elementary-step kinetics study on the $\mathrm{CO}_{2} \mathrm{RR}$ mechanism to $\mathrm{C}_{1}$ products showed the formation of either ${ }^{\star} \mathrm{CHO}$ or ${ }^{\star} \mathrm{COH}$ from ${ }^{*} \mathrm{CO}$ hydrogenation, which determines the selectivity on $\mathrm{Cu}(111)^{43} \cdot{ }^{\star} \mathrm{CH}_{x}$ species are formed via the more kinetically favourable ${ }^{\star} \mathrm{COH}$ intermediate, which eventually leads to methane and ethylene. Cell ${ }^{164}$ and charge ${ }^{162,163}$ extrapolation schemes, and constant electrode potential models ${ }^{44}$ are also available for the evaluation of energy landscapes, and recent studies have shed light on the intricacies of those methods and the important role of solvation on them ${ }^{165}$.

Recently, it was argued ${ }^{166}$ that adsorbate solvation had not been (sufficiently) taken into account in previous studies ${ }^{40,43}$, and a mechanism on $\mathrm{Cu}(111)$ was proposed in which surface water influences the selectivity towards hydrocarbons compared with alcohol products. Although solvation is crucial when attempts are made to break scaling relations, it is often overlooked or taken into account as a constant correction to the adsorption energies calculated in vacuum
(Fig. 6c) ${ }^{39,142,144,145}$. It was recently found that solvation restores the scalability broken under vacuum ${ }^{154}$ and that it strongly depends on the geometry and chemical nature of the surface sites $^{167-169}$.

Apart from the effects discussed so far, the electrolyte has been shown to alter the activity and selectivity of metal electrodes (Fig. 6c). There are two ways of incorporating ion effects in DFT simulations: implicitly and explicitly. Implicit ion effects are accounted for by means of an electric field that modifies the adsorption energies ${ }^{170}$. In explicit calculations, the ions are introduced and relaxed in the calculations, together with the adsorbates ${ }^{82,171}$. Both approaches show that $\mathrm{CO}_{2} \mathrm{RR}$ intermediates such as ${ }^{\star} \mathrm{CO}_{2},{ }^{\star} \mathrm{CO}$, ${ }^{*} \mathrm{OCCO}$ and ${ }^{\star} \mathrm{COCOH}$ are stabilized by alkaline cations, and that this stabilization is related to their polar/charged character ${ }^{30,80}$.

In short, significant progress has been made in the past decade yet numerous challenges still lie ahead, which currently prevent the development of accurate screening routines for the design of new $\mathrm{CO}_{2}$ and $\mathrm{CO}$ reduction materials ${ }^{172}$. While we need comprehensive fundamental studies that incorporate more features of real interfaces at which $\mathrm{CO}_{2} \mathrm{RR}$ takes place, we also need to make less problematic assumptions in screening studies aimed at designing novel materials. To date, reports of in silico-designed catalysts for 
a Pathway bifurcation in screening studies

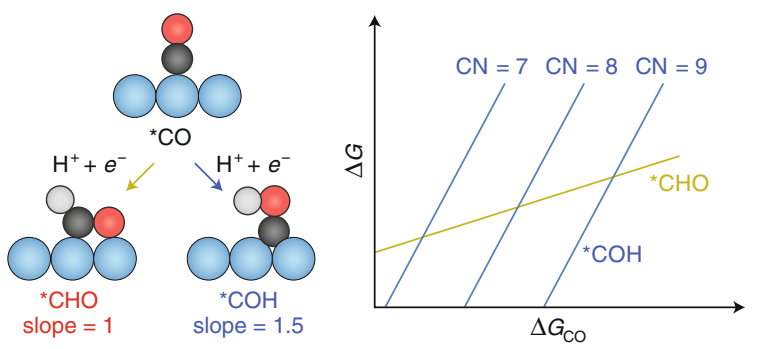

Volcano plots assume that $\mathrm{CO}_{2} \mathrm{RR}$ proceeds through a single pathway on all materials and facets. Using scaling relations, one can build material-and facet-dependent screening routines.

c Cation, anion and water solvation effects.

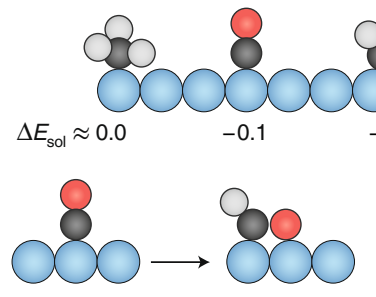

$\Delta G \approx 0.7 \mathrm{eV}$

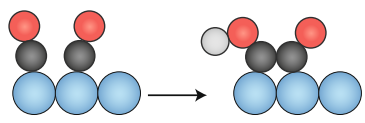

$\Delta G \approx 0.9 \mathrm{eV}$

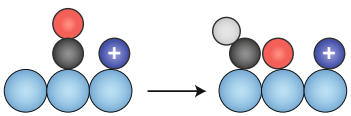

$\Delta G \approx 0.5 \mathrm{eV}$

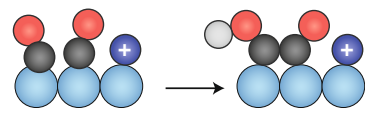

$\Delta G \approx 0.2 \mathrm{eV}$
Water stabilizes primarily intermediates with $-\mathrm{OH}$ groups.

Cations and anions can stabilize $\mathrm{CO}_{2} \mathrm{RR}$ intermediates, in particular $\mathrm{C}_{2}$ intermediates. b Kinetics of the electrochemical steps
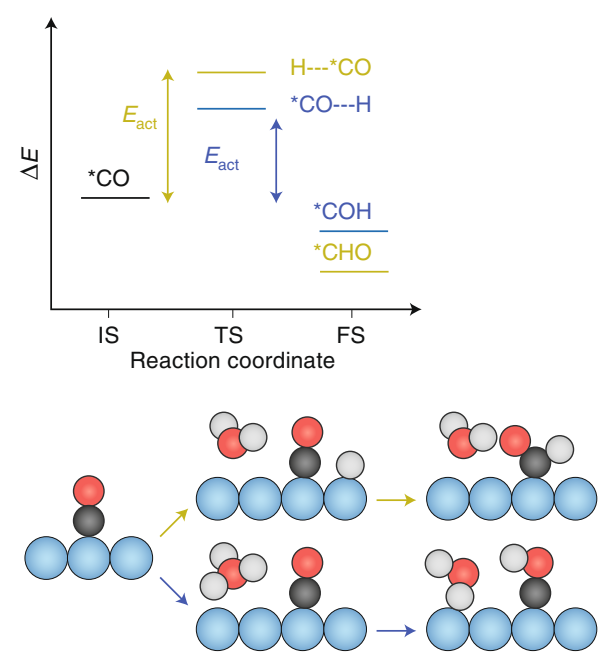

- Protons may come from $\mathrm{H}_{3} \mathrm{O}^{+}, \mathrm{H}_{2} \mathrm{O}$ or ${ }^{*} \mathrm{H}$ under $\mathrm{CO}_{2} \mathrm{RR}$ conditions.

- Thermodynamic analyses alone might, in some cases, be insufficient.

- Constant-potential barriers should be calculated, which is challenging.

Available methods:

- Cell extrapolation scheme.

- Charge extrapolation scheme.

- Hydrogen shuttling model.

- Water-solvated model.

- Constant electrode potential model.

Fig. 6 | Recent progress in descriptor-based analyses. a, Material- and facet-dependent elaboration of reaction pathways for screening studies on the example of ${ }^{\star} \mathrm{CO}$ hydrogenation, which leads to ${ }^{\star} \mathrm{CHO}$ or ${ }^{\star} \mathrm{COH}$ depending on the type of metal and its coordination. $\mathrm{CN}$, coordination number of the adsorption sites. The slopes reported are those of the scaling relations versus ${ }^{\star} \mathrm{CO}$ (ref. ${ }^{161}$ ). The colour code is provided as an inset. Panel adapted from ref. ${ }^{161}$, American Chemical Society. b, Kinetics of the electrochemical steps, which can be assessed using different approaches ${ }^{43,44,162-165}$. IS, TS and FS are the initial, transition and final states, respectively. The example shown considers ${ }^{\star} \mathrm{CO}$ hydrogenation on $\mathrm{Cu}(111)$ : while ${ }^{\star} \mathrm{CHO}$ is more stable, the barrier to produce ${ }^{\star} \mathrm{COH}$ is lower ${ }^{43}$. c, Effects of water solvation and ionic species on the relative stability of $\mathrm{CO}_{2} \mathrm{RR}$ intermediates. Adsorbates are differently stabilized by water depending on their chemical structure. $\mathrm{CO}$ hydrogenation to ${ }^{\star} \mathrm{CHO}$ is made $0.2 \mathrm{eV}$ more favourable by cations, while $\mathrm{CO}$ dimerization and hydrogenation is made $0.7 \mathrm{eV}$ more favourable by the same cations. Values taken from refs. ${ }^{39,82,144,161,167 .}$

$\mathrm{CO}_{2} / \mathrm{CO}$ reduction to hydrocarbons and/or oxygenates successfully implemented experimentally are rare. Hopefully, future advances in the treatment of $\mathrm{pH}$ - and potential-dependent reaction barriers, inclusion of solvation and electrolyte effects, and a deeper understanding of scaling relations, how and when to break or avoid them, will enable such developments. To enhance the theory-experiment interplay, more single-crystal-based onset potentials and the detection of more $\mathrm{CO}_{2} \mathrm{RR}$ intermediates would help in the validation or reformulation of DFT-based reaction pathways.

\section{Future directions}

In recent decades, significant progress has been made mainly regarding the design of highly active or selective electrocatalysts, and their $\mathrm{CO}_{2} \mathrm{RR}$ mechanism. However, it is crucial to realize the importance of other aspects, such as electrode morphology, (sub)surface structure, and reaction and process conditions, not only from a mechanistic standpoint but also from a system perspective. Specifically, not only the electrode/electrolyte interface should be studied but also transport phenomena, catalyst stability and electrolyte/solvent effects should be optimized. In this endeavour, it is desirable and even necessary to combine computational and in situ spectroelectrochemical techniques. Ideally, one would like to combine all the different aspects in a (computational) model instead of a collection of theoretical models providing only (mechanistic) information for specific cases. This would require a more rigorous standardization of experimental setups and procedures, more dedicated efforts to understand electrocatalysis beyond what happens at the catalyst surface, and a multiscale computational modelling approach encompassing all these aspects. We believe that future research should deviate from solely finding or improving highly active/selective electrocatalysts, and focus on the joint action of all relevant aspects for $\mathrm{CO}_{2} \mathrm{RR}$ to become a viable option for the production of electrofuels.

Received: 23 December 2018; Accepted: 4 July 2019;

Published online: 9 September 2019

\section{References}

1. Whipple, D. T. \& Kenis, P. J. A. Prospects of $\mathrm{CO}_{2}$ utilization via direct heterogeneous electrochemical reduction. J. Phys. Chem. Lett. 1, 3451-3458 (2010)

2. Durst, J. et al. Electrochemical $\mathrm{CO}_{2}$ reduction - a critical view on fundamentals, materials and applications. Chim. Int. J. Chem. 69, 769-776 (2015).

3. Jones, J. P., Prakash, G. K. S. \& Olah, G. A. Electrochemical $\mathrm{CO}_{2}$ reduction: recent advances and current trends. Isr. J. Chem. 54, 1451-1466 (2014).

4. Hori, Y. in Modern Aspects of Electrochemistry (eds Vayenas, C., White, R. \& Gamboa-Aldeco, M.) 89-189 (Springer, 2008). 
5. Bushuyev, O. S. et al. What should we make with $\mathrm{CO}_{2}$ and how can we make it? joule 2, 825-832 (2018).

6. Kortlever, R., Shen, J., Schouten, K. J. P., Calle-Vallejo, F. \& Koper, M. T. M. Catalysts and reaction pathways for the electrochemical reduction of carbon dioxide. J. Phys. Chem. Lett. 6, 4073-4082 (2015).

7. Seh, Z. W. et al. Combining theory and experiment in electrocatalysis: insights into materials design. Science 355, eaad4998 (2017).

8. Hori, Y., Wakebe, H., Tsukamoto, T. \& Koga, O. Electrocatalytic process of $\mathrm{CO}$ selectivity in electrochemical reduction of $\mathrm{CO}_{2}$ at metal electrodes in aqueous media. Electrochim. Acta 39, 1833-1839 (1994)

9. Kortlever, R., Peters, I., Koper, S. \& Koper, M. T. M. Electrochemical CO reduction to formic acid at low overpotential and with high Faradaic efficiency on carbon-supported bimetallic Pd-Pt nanoparticles. ACS Catal. 5, 3916-3923 (2015)

10. Armstrong, F. A. \& Hirst, J. Reversibility and efficiency in electrocatalytic energy conversion and lessons from enzymes. Proc. Natl Acad. Sci. USA 108, 14049-14054 (2011)

11. Yoo, J. S., Christensen, R., Vegge, T., Nørskov, J. K. \& Studt, F. Theoretical insight into the trends that guide the electrochemical reduction of carbon dioxide to formic acid. ChemSusChem 9, 358-363 (2016).

12. Göttle, A. J. \& Koper, M. T. M. Proton-coupled electron transfer in the electrocatalysis of $\mathrm{CO}_{2}$ reduction: prediction of sequential vs. concerted pathways using DFT. Chem. Sci. 8, 458-465 (2017).

13. Shen, J. et al. Electrocatalytic reduction of carbon dioxide to carbon monoxide and methane at an immobilized cobalt protoporphyrin. Nat. Commun. 6, 8177 (2015).

14. Shen, J., Kolb, M. J., Göttle, A. J. \& Koper, M. T. M. DFT study on the mechanism of the electrochemical reduction of $\mathrm{CO}_{2}$ catalyzed by cobalt porphyrins. J. Phys. Chem. C. 120, 15714-15721 (2016).

15. Wuttig, A., Yaguchi, M., Motobayashi, K., Osawa, M. \& Surendranath, Y Inhibited proton transfer enhances Au-catalyzed $\mathrm{CO}_{2}$-to-fuels selectivity. Proc. Natl Acad. Sci. USA 113, E4585-E4593 (2016).

16. Chen, L. D., Urushihara, M., Chan, K. \& Nørskov, J. K. Electric field effects in electrochemical $\mathrm{CO}_{2}$ reduction. ACS Catal. 6, 7133-7139 (2016).

17. Singh, M. R., Goodpaster, J. D., Weber, A. Z., Head-gordon, M. \& Bell, A. T. Mechanistic insights into electrochemical reduction of $\mathrm{CO}_{2}$ over $\mathrm{Ag}$ using density functional theory and transport models. Proc. Natl Acad. Sci. USA 114, E8812-E8821 (2017).

18. Birdja, Y. Y., Shen, J. \& Koper, M. T. M. Influence of the metal center of metalloprotoporphyrins on the electrocatalytic $\mathrm{CO}_{2}$ reduction to formic acid. Catal. Today 288, 37-47 (2017).

19. Solis, B. H., Maher, A. G., Dogutan, D. K., Nocera, D. G. \& HammesSchiffer, S. Nickel phlorin intermediate formed by proton-coupled electron transfer in hydrogen evolution mechanism. Proc. Natl Acad. Sci. USA 113, 485-492 (2016).

20. Göttle, A. J. \& Koper, M. T. M. Determinant role of the electrogenerated reactive nucleophilic species on the selectivity during the reduction of $\mathrm{CO}_{2}$ catalyzed by metalloporphyrins. J. Am. Chem. Soc. 140, 4826-4834 (2018).

21. Loewen, N. D., Neelakantan, T. V. \& Berben, L. A. Renewable formate from $\mathrm{C}-\mathrm{H}$ bond formation with $\mathrm{CO}_{2}$ : using iron carbonyl clusters as electrocatalysts. Acc. Chem. Res. 50, 2362-2370 (2017).

22. Tang, Q. et al. Lattice-hydride mechanism in electrocatalytic $\mathrm{CO}_{2}$ reduction by structurally precise copper-hydride nanoclusters. J. Am. Chem. Soc. 139, 9728-9736 (2017).

23. Min, X. \& Kanan, M. W. Pd-catalyzed electrohydrogenation of carbon dioxide to formate: high mass activity at low overpotential and identification of the deactivation pathway. J. Am. Chem. Soc. 137, 4701-4708 (2015).

24. Groenenboom, M. C. \& Keith, J. A. Quantum chemical analyses of $\mathrm{BH}_{4}^{-}$and $\mathrm{BH}_{3} \mathrm{OH}^{-}$hydride transfers to $\mathrm{CO}_{2}$ in aqueous solution with potentials of mean force. ChemPhysChem 18, 3148-3152 (2017).

25. Torelli, D. A. et al. Nickel-gallium-catalyzed electrochemical reduction of $\mathrm{CO}_{2}$ to highly reduced products at low overpotentials. ACS Catal. 6, 2100-2104 (2016).

26. Kortlever, R. et al. Palladium-gold catalyst for the electrochemical reduction of $\mathrm{CO}_{2}$ to $\mathrm{C}_{1}-\mathrm{C}_{5}$ hydrocarbons. Chem. Commun. 52, 10229-10232 (2016)

27. Calvinho, K. U. D. et al. Selective $\mathrm{CO}_{2}$ reduction to $\mathrm{C}_{3}$ and $\mathrm{C}_{4}$ oxyhydrocarbons on nickel phosphides at overpotentials as low as $10 \mathrm{mV}$. Energy Environ. Sci. 11, 2550-2559 (2018).

28. Fan, Q. et al. Electrochemical $\mathrm{CO}_{2}$ reduction to $\mathrm{C}_{2+}$ species: heterogeneous electrocatalysts, reaction pathways, and optimization strategies. Mater. Today Energy 10, 280-301 (2018).

29. Han, Z., Kortlever, R., Chen, H.-Y., Peters, J. C. \& Agapie, T. CO $\mathrm{CO}_{2}$ reduction selective for $\mathrm{C}_{\geq 2}$ products on polycrystalline copper with $\mathrm{N}$-substituted pyridinium additives. ACS Cent. Sci. 3, 853-859 (2017).

30. Hoang, T. T. H. et al. Nano porous copper-silver alloys by additivecontrolled electro-deposition for the selective electroreduction of $\mathrm{CO}_{2}$ to ethylene and ethanol. J. Am. Chem. Soc. 140, 5791-5797 (2018)
31. Dinh, C., Burdyny, T., Kibria, G., Seifitokaldani, A. \& Christine, M. $\mathrm{CO}_{2}$ electroreduction to ethylene via hydroxide-mediated copper catalysis at an abrupt interface. Science 360, 783-787 (2018).

32. Gao, D. et al. Activity and selectivity control in $\mathrm{CO}_{2}$ electroreduction to multicarbon products over $\mathrm{CuO}_{x}$ catalysts via electrolyte design. ACS Catal. 8, 10012-10020 (2018)

33. Hori, Y., Takahashi, I., Koga, O. \& Hoshi, N. Electrochemical reduction of carbon dioxide at various series of copper single crystal electrodes. J. Mol. Catal. A 199, 39-47 (2003).

34. Schouten, K. J. P., Kwon, Y., van der Ham, C. J. M., Qin, Z. \& Koper, M. T. M. A new mechanism for the selectivity to $C_{1}$ and $C_{2}$ species in the electrochemical reduction of carbon dioxide on copper electrodes. Chem. Sci. 2, 1902-1909 (2011).

35. Schouten, K., Gallent, E. \& Koper, M. Structure sensitivity of the electrochemical reduction of carbon monoxide on copper single crystals. ACS Catal. 4, 1292-1295 (2013).

36. Schouten, K. J. P., Qin, Z., Gallent, E. P. \& Koper, M. T. M. Two pathways for the formation of ethylene in $\mathrm{CO}$ reduction on single-crystal copper electrodes. J. Am. Chem. Soc. 134, 9864-9867 (2012).

37. Gattrell, M., Gupta, N. \& Co, A. A review of the aqueous electrochemica reduction of $\mathrm{CO}_{2}$ to hydrocarbons at copper. J. Electroanal. Chem. 594, 1-19 (2006).

38. Wuttig, A. et al. Tracking a common surface-bound intermediate during $\mathrm{CO}_{2}$-to-fuels catalysis. ACS Cent. Sci. 2, 522-528 (2016).

39. Calle-Vallejo, F. \& Koper, M. T. M. Theoretical considerations on the electroreduction of $\mathrm{CO}$ to $\mathrm{C}_{2}$ species on $\mathrm{Cu}(100)$ electrodes. Angew. Chem. Int. Ed. 52, 7282-7285 (2013).

40. Montoya, J. H., Shi, C., Chan, K. \& Nørskov, J. K. Theoretical insights into $\mathrm{CO}$ dimerization mechanism in $\mathrm{CO}_{2}$ electroreduction. J. Phys. Chem. Lett. 6, 2032-2037 (2015).

41. Goodpaster, J. D., Bell, A. T. \& Head-Gordon, M. Identification of possible pathways for $\mathrm{C}-\mathrm{C}$ bond formation during electrochemical reduction of $\mathrm{CO}_{2}$ : new theoretical insights from an improved electrochemical model J. Phys. Chem. Lett. 7, 1471-1477 (2016).

42. Li, H., Li, Y., Koper, M. T. M. \& Calle-Vallejo, F. Bond making and breaking between carbon, nitrogen and oxygen in electrocatalysis. J. Am. Chem. Soc. 136, 15694-15701 (2014).

43. Nie, X., Esopi, M. R., Janik, M. J. \& Asthagiri, A. Selectivity of $\mathrm{CO}_{2}$ reduction on copper electrodes: the role of the kinetics of elementary steps. Angew. Chem. Int. Ed. 52, 2459-2462 (2013).

44. Garza, A., Bell, A. T. \& Head-Gordon, M. Mechanism of $\mathrm{CO}_{2}$ reduction at copper surfaces: pathways to $\mathrm{C}_{2}$ products. ACS Catal. 8 , 1490-1499 (2018)

45. Pérez-Gallent, E., Figueiredo, M. C., Calle-Vallejo, F. \& Koper, M. T. M Spectroscopic observation of a hydrogenated CO dimer intermediate during $\mathrm{CO}$ reduction on $\mathrm{Cu}(100)$ electrodes. Angew. Chem. Int. Ed. $\mathbf{5 6}$ 3621-3624 (2017).

46. Kas, R., Kortlever, R., Yilmaz, H., Koper, M. T. M. \& Mul, G. Manipulating the hydrocarbon selectivity of copper nanoparticles in $\mathrm{CO}_{2}$ electroreduction by process conditions. ChemElectroChem 2, 354-358 (2015).

47. Hanselman, S., Koper, M. T. M. \& Calle-Vallejo, F. Computational comparison of late transition metal (100) surfaces for the electrocatalytic reduction of CO to $\mathrm{C}_{2}$ species. ACS Energy Lett. 3, 1062-1067 (2018).

48. Ledezma-Yanez, I., Gallent, E. P., Koper, M. T. M. \& Calle-Vallejo, F. Structure-sensitive electroreduction of acetaldehyde to ethanol on copper and its mechanistic implications for $\mathrm{CO}$ and $\mathrm{CO}_{2}$ reduction. Catal. Today 262, 90-94 (2016).

49. Hahn, C. et al. Engineering $\mathrm{Cu}$ surfaces for the electrocatalytic conversion of $\mathrm{CO}_{2}$ : controlling selectivity toward oxygenates and hydrocarbons. Proc. Natl Acad. Sci. USA 114, 5918-5923 (2017).

50. Ren, D., Ang, B. S.-H. \& Yeo, B. S. Tuning the selectivity of carbon dioxide electroreduction toward ethanol on oxide-derived $\mathrm{Cu}_{x} \mathrm{Zn}$ catalysts. ACS Catal. 6, 8239-8247 (2016).

51. Liu, Y., Chen, S., Quan, X. \& Yu, H. Efficient electrochemical reduction of carbon dioxide to acetate on nitrogen-doped nanodiamond. J. Am. Chem. Soc. 137, 11631-11636 (2015).

52. Genovese, C., Ampelli, C., Perathoner, S. \& Centi, G. Mechanism of C-C bond formation in the electrocatalytic reduction of $\mathrm{CO}_{2}$ to acetic acid. A challenging reaction to use renewable energy with chemistry. Green. Chem. 19, 2406-2415 (2017)

53. Birdja, Y. Y. \& Koper, M. T. M. The importance of Cannizzaro-type reactions during electrocatalytic reduction of carbon dioxide. J. Am. Chem. Soc. 139, 2030-2034 (2017).

54. Zhuang, T. T. et al. Copper nanocavities confine intermediates for efficient electrosynthesis of C3 alcohol fuels from carbon monoxide. Nat. Catal. 1, 946-951 (2018).

55. Kuhl, K. P., Cave, E. R., Abram, D. N. \& Jaramillo, T. F. New insights into the electrochemical reduction of carbon dioxide on metallic copper surfaces. Energy Environ. Sci. 5, 7050-7059 (2012). 
56. Ren, D., Wong, N. T., Handoko, A. D., Huang, Y. \& Yeo, B. S. Mechanistic insights into the enhanced activity and stability of agglomerated $\mathrm{Cu}$ nanocrystals for the electrochemical reduction of carbon dioxide to n-propanol. J. Phys. Chem. Lett. 7, 20-24 (2016).

57. Singh, M. R. et al. Effects of electrolyte, catalyst, and membrane composition and operating conditions on the performance of solar-driven electrochemical reduction of carbon dioxide. Phys. Chem. Chem. Phys. 17, 18924-18936 (2015)

58. Clark, E. L. et al. Standards and protocols for data acquisition and reporting for studies of the electrochemical reduction of carbon dioxide. ACS Catal. 8, 6560-6570 (2018).

59. Zhong, H., Fujii, K., Nakano, Y. \& Jin, F. Effect of $\mathrm{CO}_{2}$ bubbling into aqueous solutions used for electrochemical reduction of $\mathrm{CO}_{2}$ for energy conversion and storage. J. Phys. Chem. C. 119, 55-61 (2015).

60. Sreekanth, N. \& Phani, K. L. Selective reduction of $\mathrm{CO}_{2}$ to formate through bicarbonate reduction on metal electrodes: new insights gained from SG/ TC mode of SECM. Chem. Commun. 50, 11143-11146 (2014).

61. Kortlever, R., Tan, K. H., Kwon, Y. \& Koper, M. T. M. Electrochemical carbon dioxide and bicarbonate reduction on copper in weakly alkaline media. J. Solid State Electrochem. 17, 1843-1849 (2013).

62. Innocent, B. et al. FTIR spectroscopy study of the reduction of carbon dioxide on lead electrode in aqueous medium. Appl. Catal. B 94, 219-224 (2010).

63. Dunwell, M. et al. The central role of bicarbonate in the electrochemical reduction of carbon dioxide on gold. J. Am. Chem. Soc. 139, 3774-3783 (2017)

64. Zhu, S., Jiang, B., Cai, W. Bin \& Shao, M. Direct observation on reaction intermediates and the role of bicarbonate anions in $\mathrm{CO}_{2}$ electrochemical reduction reaction on Cu surfaces. J. Am. Chem. Soc. 139 , 15664-15667 (2017).

65. Wuttig, A., Yoon, Y., Ryu, J. \& Surendranath, Y. Bicarbonate is not a general acid in Au-catalyzed $\mathrm{CO}_{2}$ electroreduction. J. Am. Chem. Soc. 139, 17109-17113 (2017).

66. Resasco, J., Lum, Y., Clark, E., Zeledon, J. Z. \& Bell, A. T. Effects of anion identity and concentration on electrochemical reduction of $\mathrm{CO}_{2}$ ChemElectroChem 5, 1064-1072 (2018).

67. Varela, A. S., Kroschel, M., Reier, T. \& Strasser, P. Controlling the selectivity of $\mathrm{CO}_{2}$ electroreduction on copper: the effect of the electrolyte concentration and the importance of the local pH. Catal. Today 260, 8-13 (2016).

68. Dunwell, M. et al. Examination of near-electrode concentration gradients and kinetic impacts on the electrochemical reduction of $\mathrm{CO}_{2}$ using surface-enhanced infrared spectroscopy. ACS Catal. 8, 3999-4008 (2018).

69. Gupta, N., Gattrell, M. \& MacDougall, B. Calculation for the cathode surface concentrations in the electrochemical reduction of $\mathrm{CO}_{2}$ in $\mathrm{KHCO}_{3}$ solutions. J. Appl. Electrochem. 36, 161-172 (2006).

70. Hashiba, H. et al. Effects of electrolyte buffer capacity on surface reactant species and reaction rate of $\mathrm{CO}_{2}$ in electrochemical $\mathrm{CO}_{2}$ reduction. J. Phys. Chem. C. 122, 3719-3726 (2018).

71. Liu, X. et al. pH effects on the electrochemical reduction of $\mathrm{CO}_{(2)}$ towards $\mathrm{C}_{2}$ products on stepped copper. Nat. Commun. 10, 32 (2019).

72. Hori, Y., Murata, A. \& Takahashi, R. Formation of hydrocarbons in the electrochemical reduction of carbon dioxide at a copper electrode in aqueous solution. J. Chem. Soc. Faraday Trans. 1 85, 2309-2326 (1989).

73. Yoon, Y., Hall, A. S. \& Surendranath, Y. Tuning of silver catalyst mesostructure promotes selective carbon dioxide conversion into fuels. Angew. Chem. Int. Ed. 55, 15282-15286 (2016).

74. Hall, A. S., Yoon, Y., Wuttig, A. \& Surendranath, Y. Mesostructureinduced selectivity in $\mathrm{CO}_{2}$ reduction catalysis. J. Am. Chem. Soc. 137, 14834-14837 (2015).

75. Lim, C. F. C., Harrington, D. A. \& Marshall, A. T. Effects of mass transfer on the electrocatalytic $\mathrm{CO}_{2}$ reduction on Cu. Electrochim. Acta 238 , 56-63 (2017).

76. Ooka, H., Figueiredo, M. C. \& Koper, M. T. M. Competition between hydrogen evolution and carbon dioxide reduction on copper electrodes in mildly acidic media. Langmuir 33, 9307-9313 (2017).

77. Luca, O. R. \& Fenwick, A. Q. Organic reactions for the electrochemical and photochemical production of $\mathrm{CO}_{2}$ to fuels - the reduction chemistry of carboxylic acids as bent $\mathrm{CO}_{2}$ surrogates, aldehydes, alcohols and alkyls. J. Photochem. Photobiol. B 152, 26-42 (2015).

78. Murata, A. \& Hori, Y. Product selectivity affected by cationic species in electrochemical reduction of $\mathrm{CO}_{2}$ and $\mathrm{CO}$ at a $\mathrm{Cu}$ electrode. Bull. Chem. Soc. Jpn 64, 123-127 (1991).

79. Singh, M. R., Kwon, Y., Lum, Y., Ager, J. W. \& Bell, A. T. Hydrolysis of electrolyte cations enhances the electrochemical reduction of $\mathrm{CO}_{2}$ over $\mathrm{Ag}$ and Cu. J. Am. Chem. Soc. 138, 13006-13012 (2016).

80. Thorson, M. R., Siil, K. I. \& Kenis, P. J. A. Effect of cations on the electrochemical conversion of $\mathrm{CO}_{2}$ to CO. J. Electrochem. Soc. 160, F69-F74 (2013).
81. Resasco, J. et al. Promoter effects of alkali metal cations on the electrochemical reduction of carbon dioxide. J. Am. Chem. Soc. 139, 11277-11287 (2017).

82. Pérez-Gallent, E., Marcandalli, G., Figueiredo, M. C., Calle-Vallejo, F. \& Koper, M. T. M. Structure- and potential-dependent cation effects on CO reduction at copper single-crystal electrodes. J. Am. Chem. Soc. 139, 16412-16419 (2017).

83. Yano, H., Tanaka, T., Nakayama, M. \& Ogura, K. Selective electrochemical reduction of $\mathrm{CO}_{2}$ to ethylene at a three-phase interface on copper(I) halide-confined $\mathrm{Cu}$-mesh electrodes in acidic solutions of potassium halides. J. Electroanal. Chem. 565, 287-293 (2004).

84. Ogura, K., Ferrell, J. R., Cugini, A. V., Smotkin, E. S. \& Salazar-Villalpando, M. D. $\mathrm{CO}_{2}$ attraction by specifically adsorbed anions and subsequent accelerated electrochemical reduction. Electrochim. Acta $\mathbf{5 6}$ 381-386 (2010).

85. Varela, A. S., Ju, W., Reier, T. \& Strasser, P. Tuning the catalytic activity and selectivity of $\mathrm{Cu}$ for $\mathrm{CO}_{2}$ electroreduction in the presence of halides. ACS Catal. 6, 2136-2144 (2016).

86. Gao, D., Scholten, F. \& Roldan Cuenya, B. Improved $\mathrm{CO}_{2}$ electroreduction performance on plasma-activated $\mathrm{Cu}$ catalysts via electrolyte design: halide effect. ACS Catal. 7, 5112-5120 (2017).

87. Huang, Y., Ong, C. W. \& Yeo, B. S. Effects of electrolyte anions on the reduction of carbon dioxide to ethylene and ethanol on copper (100) and (111) surfaces. ChemSusChem 11, 3299-3306 (2018).

88. Tang, W. et al. The importance of surface morphology in controlling the selectivity of polycrystalline copper for $\mathrm{CO}_{2}$ electroreduction. Phys. Chem. Chem. Phys. 14, 76-81 (2012).

89. Roberts, F. S., Kuhl, K. P. \& Nilsson, A. High selectivity for ethylene from carbon dioxide reduction over copper nanocube electrocatalysts. Angew. Chem. Int. Ed. 54, 5179-5182 (2015).

90. Loiudice, A. et al. Tailoring copper nanocrystals towards $\mathrm{C}_{2}$ products in electrochemical $\mathrm{CO}_{2}$ reduction. Angew. Chem. Int. Ed. 55, 5789-5792 (2016).

91. Sen, S., Liu, D. \& Palmore, G. T. R. Electrochemical reduction of $\mathrm{CO}_{2}$ at copper nanofoams. ACS Catal. 4, 3091-3095 (2014).

92. Reske, R., Mistry, H., Behafarid, F., Roldan Cuenya, B. \& Strasser, P. Particle size effects in the catalytic electroreduction of $\mathrm{CO}_{2}$ on $\mathrm{Cu}$ nanoparticles. I. Am. Chem. Soc. 136, 6978-6986 (2014).

93. Yang, K. D. et al. Morphology-directed selective production of ethylene or ethane from $\mathrm{CO}_{2}$ on a $\mathrm{Cu}$ mesopore electrode. Angew. Chem. Int. Ed. 56, 796-800 (2017).

94. Chen, C. S. et al. Stable and selective electrochemical reduction of carbon dioxide to ethylene on copper mesocrystals. Catal. Sci. Technol. 5, 161-168 (2015)

95. Mistry, H. et al. Tuning catalytic selectivity at the mesoscale via interparticle interactions. ACS Catal. 6, 1075-1080 (2016).

96. Kas, R. et al. Three-dimensional porous hollow fibre copper electrodes for efficient and high-rate electrochemical carbon dioxide reduction. Nat. Commun. 7, 10748 (2016)

97. $\mathrm{Li}, \mathrm{C} . \mathrm{W}$. \& Kanan, M. W. $\mathrm{CO}_{2}$ reduction at low overpotential on $\mathrm{Cu}$ electrodes resulting from the reduction of thick $\mathrm{Cu}_{2} \mathrm{O}$ films. J. Am. Chem. Soc. 134, 7231-7234 (2012).

98. Lee, C. H. \& Kanan, M. W. Controlling $\mathrm{H}^{+}$vs $\mathrm{CO}_{2}$ reduction selectivity on $\mathrm{Pb}$ electrodes. ACS Catal. 5, 465-469 (2015).

99. Dutta, A., Rahaman, M., Luedi, N. C., Mohos, M. \& Broekmann, P. Morphology matters: tuning the product distribution of $\mathrm{CO}_{2}$ electroreduction on oxide-derived $\mathrm{Cu}$ foam catalysts. ACS Catal. 6 , 3804-3814 (2016).

100. Ma, M., Djanashvili, K. \& Smith, W. A. Selective electrochemical reduction of $\mathrm{CO}_{2}$ to $\mathrm{CO}$ on $\mathrm{CuO}$-derived $\mathrm{Cu}$ nanowires. Phys. Chem. Chem. Phys. 17, 20861-20867 (2015)

101. Kas, R. et al. Electrochemical $\mathrm{CO}_{2}$ reduction on $\mathrm{Cu}_{2} \mathrm{O}$-derived copper nanoparticles: controlling the catalytic selectivity of hydrocarbons. Phys. Chem. Chem. Phys. 16, 12194-201 (2014).

102. Li, C. W., Ciston, J. \& Kanan, M. W. Electroreduction of carbon monoxide to liquid fuel on oxide-derived nanocrystalline copper. Nature 508, 504-507 (2014)

103. Chen, Y., Li, C. W. \& Kanan, M. W. Aqueous $\mathrm{CO}_{2}$ reduction at very low overpotential on oxide-derived Au nanoparticles. J. Am. Chem. Soc. 134, 19969-19972 (2012).

104. Ma, M., Trześniewski, B. J., Xie, J. \& Smith, W. A. Selective and efficient reduction of carbon dioxide to carbon monoxide on oxide-derived nanostructured silver electrocatalysts. Angew. Chem. Int. Ed. 55, 9748-9752 (2016).

105. Pander, J. E. et al. Understanding the heterogeneous electrocatalytic reduction of carbon dioxide on oxide-derived catalysts. ChemElectroChem 5, 219-237 (2018).

106. Zhu, W. et al. Monodisperse Au nanoparticles for selective electrocatalytic reduction of $\mathrm{CO}_{2}$ to CO. J. Am. Chem. Soc. 135, 16833-16836 (2013) 
107. Mistry, H. et al. Exceptional size-dependent activity enhancement in the electroreduction of $\mathrm{CO}_{2}$ over Au nanoparticles. J. Am. Chem. Soc. 136 16473-16476 (2014).

108. Feng, X., Jiang, K., Fan, S. \& Kanan, M. W. A direct grain-boundary-activity correlation for $\mathrm{CO}$ electroreduction on $\mathrm{Cu}$ nanoparticles. ACS Cent. Sci. 2, 169-174 (2016).

109. Verdaguer-Casadevall, A. et al. Probing the active surface sites for CO reduction on oxide-derived copper electrocatalysts. J. Am. Chem. Soc. 137, 9808-9811 (2015).

110. Eilert, A. et al. Subsurface Oxygen in oxide-derived copper electrocatalysts for carbon dioxide reduction. J. Phys. Chem. Lett. 8, 285-290 (2017).

111. Mariano, R. G., McKelvey, K., White, H. S. \& Kanan, M. W. Selective increase in $\mathrm{CO}_{2}$ electroreduction activity at grain-boundary surface terminations. Science 358, 1187-1192 (2017).

112. Mistry, H. et al. Highly selective plasma-activated copper catalysts for carbon dioxide reduction to ethylene. Nat. Commun. 7, 12123 (2016).

113. Mistry, H. et al. Enhanced carbon dioxide electroreduction to carbon monoxide over defect-rich plasma-activated silver catalysts. Angew. Chem. Int. Ed. 56, 11394-11398 (2017).

114. Favaro, M. et al. Subsurface oxide plays a critical role in $\mathrm{CO}_{2}$ activation by $\mathrm{Cu}(111)$ surfaces to form chemisorbed $\mathrm{CO}_{2}$, the first step in reduction of $\mathrm{CO}_{2}$. Proc. Natl Acad. Sci. USA 114, 6706-6711 (2017).

115. Xiao, J., Kuc, A., Frauenheim, T. \& Heine, T. $\mathrm{CO}_{2}$ reduction at low overpotential on $\mathrm{Cu}$ electrodes in the presence of impurities at the subsurface. J. Mater. Chem. A 2, 4885-4889 (2014).

116. Fields, M., Hong, X., Norskov, J. K. \& Chan, K. The role of subsurface oxygen on $\mathrm{Cu}$ surfaces for $\mathrm{CO}_{2}$ electrochemical reduction. J. Phys. Chem. C. 122, 16209-16215 (2018).

117. Lum, Y. \& Ager, J. W. Stability of residual oxides in oxide-derived copper catalysts for electrochemical $\mathrm{CO}_{2}$ reduction investigated with ${ }^{18} \mathrm{O}$ labeling. Angew. Chem. Int. Ed. 57, 551-554 (2018).

118. Garza, A. J., Bell, A. T. \& Head-Gordon, M. Is subsurface oxygen necessary for the electrochemical reduction of $\mathrm{CO}_{2}$ on copper. J. Phys. Chem. Lett. 9, 601-606 (2018).

119. Jiang, $\mathrm{K}$. et al. Metal ion cycling of $\mathrm{Cu}$ foil for selective $\mathrm{C}-\mathrm{C}$ coupling in electrochemical $\mathrm{CO}_{2}$ reduction. Nat. Catal. 1, 111-119 (2018).

120. Cheng, T., Xiao, H. \& Goddard, W. A. Nature of the active sites for CO reduction on copper nanoparticles; suggestions for optimizing performance. J. Am. Chem. Soc. 139, 11642-11645 (2017).

121. Le, M. et al. Electrochemical reduction of $\mathrm{CO}_{2}$ to $\mathrm{CH}_{3} \mathrm{OH}$ at copper oxide surfaces. J. Electrochem. Soc. 158, E45-E49 (2011).

122. Frese, K. W. Electrochemical reduction of $\mathrm{CO}_{2}$ at intentionally oxidized copper electrodes. J. Electrochem. Soc. 138, 3338-3344 (1991).

123. Ren, D. et al. Selective electrochemical reduction of carbon dioxide to ethylene and ethanol on copper(I) oxide catalysts. ACS Catal. 5, 2814-2821 (2015).

124. Chi, D. et al. Morphology-controlled $\mathrm{CuO}$ nanoparticles for electroreduction of $\mathrm{CO}_{2}$ to ethanol. RSC Adv 4, 37329-37332 (2014).

125. Kim, D. et al. Insights into an autonomously formed oxygen-evacuated $\mathrm{Cu}_{2} \mathrm{O}$ electrode for the selective production of $\mathrm{C}_{2} \mathrm{H}_{4}$ from $\mathrm{CO}_{2}$. Phys. Chem. Chem. Phys. 17, 824-830 (2015).

126. Lee, S., Kim, D. \& Lee, J. Electrocatalytic production of $\mathrm{C} 3-\mathrm{C} 4$ compounds by conversion of $\mathrm{CO}_{2}$ on a chloride-induced bi-phasic $\mathrm{Cu}_{2} \mathrm{O}-\mathrm{Cu}$ catalyst. Angew. Chem. Int. Ed. 54, 14701-14705 (2015).

127. Le Duff, C. S., Lawrence, M. J. \& Rodriguez, P. Role of the adsorbed oxygen species in the selective electrochemical reduction of $\mathrm{CO}_{2}$ to alcohols and carbonyls on copper electrodes. Angew. Chem. Int. Ed. 56, 12919-12924 (2017).

128. Ren, D., Fong, J. \& Yeo, B. S. The effects of currents and potentials on the selectivities of copper toward carbon dioxide electroreduction. Nat. Commun. 9, 925 (2018).

129. Trasatti, S. \& Petrii, O. A. Real surface area measurement in electrochemistry. Pure Appl. Chem. 63, 711-734 (1991)

130. McCrory, C. C. L., Jung, S., Peters, J. C. \& Jaramillo, T. F. Benchmarking heterogeneous electrocatalysts for the oxygen evolution reaction. J. Am. Chem. Soc. 135, 16977-16987 (2013).

131. Heyes, J., Dunwell, M. \& Xu, B. $\mathrm{CO}_{2}$ reduction on $\mathrm{Cu}$ at low overpotentials with surface-enhanced in situ spectroscopy. J. Phys. Chem. C. 120 17334-17341 (2016)

132. Gunathunge, C. M. et al. Spectroscopic observation of reversible surface reconstruction of copper electrodes under $\mathrm{CO}_{2}$ reduction. J. Phys. Chem. C. 121, 12337-12344 (2017).

133. Pander, J. E., Baruch, M. F. \& Bocarsly, A. B. Probing the mechanism of aqueous $\mathrm{CO}_{2}$ reduction on post-transition-metal electrodes using ATR-IR spectroelectrochemistry. ACS Catal. 6, 7824-7833 (2016).

134. Cheng, T., Fortunelli, A. \& Goddard, W. A. Reaction intermediates during operando electrocatalysis identified from full solvent quantum mechanics molecular dynamics. Proc. Natl Acad. Sci. USA 116, 7718-7722 (2019).
135. Ayemoba, O. \& Cuesta, A. Spectroscopic evidence of size-dependent buffering of interfacial $\mathrm{pH}$ by cation hydrolysis during $\mathrm{CO}_{2}$ electroreduction. ACS Appl. Mater. Interfaces 9, 27377-27382 (2017).

136. Figueiredo, M. C., Ledezma-Yanez, I. \& Koper, M. T. M. In situ spectroscopic study of $\mathrm{CO}_{2}$ electroreduction at copper electrodes in acetonitrile. ACS Catal. 6, 2382-2392 (2016).

137. Eilert, A., Roberts, F. S., Friebel, D. \& Nilsson, A. Formation of copper catalysts for $\mathrm{CO}_{2}$ reduction with high ethylene/methane product ratio investigated with in situ x-ray absorption spectroscopy. J. Phys. Chem. Lett. 7, 1466-1470 (2016).

138. Choi, Y. W., Mistry, H. \& Roldan Cuenya, B. New insights into working nanostructured electrocatalysts through operando spectroscopy and microscopy. Curr. Opin. Electrochem. 1, 95-103 (2017).

139. Handoko, A. D., Wei, F., Jenndy, Yeo, B. S. \& Seh, Z. W. Understanding heterogeneous electrocatalytic carbon dioxide reduction through operando techniques. Nat. Catal. 1, 922-934 (2018).

140. Zhu, S., Li, T., Cai, W.-B. \& Shao, M. $\mathrm{CO}_{2}$ electrochemical reduction as probed through infrared spectroscopy. ACS Energy Lett. 4, 682-689 (2019).

141. Rendón-Calle, A., Builes, S. \& Calle-Vallejo, F. A brief review of the computational modeling of $\mathrm{CO}_{2}$ electroreduction on $\mathrm{Cu}$ electrodes. Curr. Opin. Electrochem. 9, 158-165 (2018).

142. Nørskov, J. K. et al. Origin of the overpotential for oxygen reduction at a fuel-cell cathode. J. Phys. Chem. B 108, 17886-17892 (2004).

143. Hansen, H. A., Rossmeisl, J. \& Nørskov, J. K. Surface Pourbaix diagrams and oxygen reduction activity of $\mathrm{Pt}, \mathrm{Ag}$ and $\mathrm{Ni}(111)$ surfaces studied by DFT. Phys. Chem. Chem. Phys. 10, 3722-3730 (2008).

144. Peterson, A. A. et al. How copper catalyzes the electroreduction of carbon dioxide into hydrocarbon fuels. Energy Environ. Sci. 3, 1311-1315 (2010).

145. Peterson, A. \& Nørskov, J. Activity descriptors for $\mathrm{CO}_{2}$ electroreduction to methane on transition metal catalysts. J. Phys. Chem. Lett. 3, 251-258 (2012).

146. Saravanan, K., Basdogan, Y., Dean, J. \& Keith, J. A. Computational investigation of $\mathrm{CO}_{2}$ electroreduction on tin oxide and predictions of $\mathrm{Ti}, \mathrm{V}$, $\mathrm{Nb}$ and $\mathrm{Zr}$ dopants for improved catalysis. J. Mater. Chem. A 5, 11756-11763 (2017).

147. Saravanan, K., Gottlieb, E. \& Keith, J. A. Nitrogen-doped nanocarbon materials under electroreduction operating conditions and implications for electrocatalysis of $\mathrm{CO}_{2}$. Carbon 111, 859-866 (2017).

148. Koper, M. T. M. Theory of the transition from sequential to concerted electrochemical proton-electron transfer. Phys. Chem. Chem. Phys. 15, 1399-1407 (2013).

149. Koper, M. T. M. Activity volcanoes for the electrocatalysis of homolytic and heterolytic hydrogen evolution. J. Solid State Electrochem. 20, 895-899 (2016).

150. Abild-Pedersen, F. et al. Scaling properties of adsorption energies for hydrogen-containing molecules on transition-metal surfaces. Phys. Rev. Lett. 99, 4-7 (2007).

151. Montemore, M. M. \& Medlin, J. W. Scaling relations between adsorption energies for computational screening and design of catalysts. Catal. Sci. Technol. 4, 3748-3761 (2014).

152. Greeley, J. Theoretical heterogeneous catalysis: scaling relationships and computational catalyst design. Annu. Rev. Chem. Biomol. Eng. 7, 605-635 (2016).

153. Govindarajan, N., García-Lastra, J. M., Meijer, E. J. \& Calle-Vallejo, F. Does the breaking of adsorption-energy scaling relations guarantee enhanced electrocatalysis? Curr. Opin. Electrochem. 8, 110-117 (2018).

154. Calle-Vallejo, F., Krabbe, A. \& Garcia-Lastra, J. M. How covalence breaks adsorption-energy scaling relations and solvation restores them. Chem. Sci. 8, 124-130 (2017).

155. Shin, H., Ha, Y. \& Kim, H. 2D covalent metals: a new materials domain of electrochemical $\mathrm{CO}_{2}$ conversion with broken scaling relationship. J. Phys. Chem. Lett. 7, 4124-4129 (2016).

156. Hansen, H. A., Varley, J. B., Peterson, A. A. \& Norskov, J. K. Understanding trends in the electrocatalytic activity of metals and enzymes for $\mathrm{CO}_{2}$ reduction to CO. J. Phys. Chem. Lett. 4, 388-392 (2013).

157. Li, Y. \& Sun, Q. Recent advances in breaking scaling relations for effective electrochemical conversion of $\mathrm{CO}_{2}$. Adv. Energy Mater. 6, 1-19 (2016).

158. Akhade, S. A., Luo, W., Nie, X., Asthagiri, A. \& Janik, M. J. Theoretical insight on reactivity trends in $\mathrm{CO}_{2}$ electroreduction across transition metals. Catal. Sci. Technol. 6, 1042-1053 (2016).

159. Cheng, M. J., Kwon, Y., Head-Gordon, M. \& Bell, A. T. Tailoring metal-porphyrin-like active sites on graphene to improve the efficiency and selectivity of electrochemical $\mathrm{CO}_{2}$ reduction. J. Phys. Chem. C. 119, 21345-21352 (2015).

160. Khorshidi, A., Violet, J., Hashemi, J. \& Peterson, A. A. How strain can break the scaling relations of catalysis. Nat. Catal. 1, 263-268 (2018).

161. Calle-Vallejo, F. \& Koper, M. T. M. Accounting for bifurcating pathways in the screening for $\mathrm{CO}_{2}$ reduction catalysts. ACS Catal. 7, 7346-7351 (2017) 
162. Shi, C., Chan, K., Yoo, J. S. \& Nørskov, J. K. Barriers of electrochemical $\mathrm{CO}_{2}$ reduction on transition metals. Org. Process Res. Dev. 20, 1424-1430 (2016).

163. Chan, K. \& Nørskov, J. K. Electrochemical barriers made simple. J. Phys. Chem. Lett. 6, 2663-2668 (2015).

164. Hussain, J., Jónsson, H. \& Skúlason, E. Calculations of product selectivity in electrochemical $\mathrm{CO}_{2}$ reduction calculations of product selectivity in electrochemical $\mathrm{CO}_{2}$ reduction. ACS Catal. 8, 5240-5249 (2018).

165. Gauthier, J. A. et al. Challenges in modeling electrochemical reaction energetics with polarizable continuum models. ACS Catal. 9, 920-931 (2019).

166. Xiao, H., Cheng, T. \& Goddard, W. A. Atomistic mechanisms underlying selectivities in $\mathrm{C}_{1}$ and $\mathrm{C}_{2}$ products from electrochemical reduction of $\mathrm{CO}$ on $\mathrm{Cu}(111)$. J. Am. Chem. Soc. 139, 130-136 (2017).

167. He, Z.-D., Hanselman, S., Chen, Y. X., Koper, M. T. M. \& Calle-Vallejo, F. Importance of solvation for the accurate prediction of oxygen reduction activities of Pt-based electrocatalysts. J. Phys. Chem. Lett. 8, 2243-2246 (2017).

168. Tripkovic, V. Thermodynamic assessment of the oxygen reduction activity in aqueous solutions. Phys. Chem. Chem. Phys. 19, 29381-29388 (2017).

169. Ludwig, T. et al. Solvent-adsorbate interactions and adsorbate-specific solvent structure in carbon dioxide reduction on a stepped $\mathrm{Cu}$ surface. J. Phys. Chem. C. 123, 5999-6009 (2019).

170. Resasco, J. et al. Promoter effects of alkali metal cations on the electrochemical reduction of carbon dioxide. J. Am. Chem. Soc. 139, 11277-11287 (2017).

171. Akhade, S. A., McCrum, I. T. \& Janik, M. J. The impact of specifically adsorbed ions on the copper-catalyzed electroreduction of $\mathrm{CO}_{2}$. J. Electrochem. Soc. 163, F477-F484 (2016).

172. Jovanov, Z. P. et al. Opportunities and challenges in the electrocatalysis of $\mathrm{CO}_{2}$ and $\mathrm{CO}$ reduction using bifunctional surfaces: a theoretical and experimental study of Au-Cd alloys. J. Catal. 343, 215-231 (2016).
173. Cave, E. R. et al. Electrochemical $\mathrm{CO}_{2}$ reduction on $\mathrm{Au}$ surfaces: mechanistic aspects regarding the formation of major and minor products. Phys. Chem. Chem. Phys. 19, 15856-15863 (2017).

174. Hatsukade, T., Kuhl, K. P., Cave, E. R., Abram, D. N. \& Jaramillo, T. F. Insights into the electrocatalytic reduction of $\mathrm{CO}_{2}$ on metallic silver surfaces. Phys. Chem. Chem. Phys. 16, 13814-13819 (2014).

175. Frese Jr., K. W., Leach, S. C. \& Summers, D. P. Electrochemical reduction of aqueous carbon dioxide to methanol. US patent 4609441A (1986).

176. Song, Y. et al. High-selectivity electrochemical conversion of $\mathrm{CO}_{2}$ to ethanol using a copper nanoparticle/ $\mathrm{N}$-doped graphene electrode. ChemistrySelect 1, 6055-6061 (2016).

\section{Acknowledgements}

The work by M.C.F. was partially funded by Bayer MaterialScience/Covestro. The work by A.J.G. was made possible by financial support of NWO and Shell Global Solutions International B.V., as part of the programme ' $\mathrm{CO}_{2}$ neutral fuels' of the Foundation for Fundamental Research on Matter (FOM). F.C.-V. thanks the Spanish MICIU for a Ramón y Cajal contract (RYC-2015-18996) and financial support through the program 'Units of Excellence María de Maeztu' (grant MDM-2017-0767).

\section{Competing interests}

The authors declare no competing interests.

\section{Additional information}

Reprints and permissions information is available at www.nature.com/reprints.

Correspondence should be addressed to F.C.-V. or M.T.M.K.

Publisher's note: Springer Nature remains neutral with regard to jurisdictional claims in published maps and institutional affiliations.

(c) Springer Nature Limited 2019 